\title{
A DFT study on the interaction of small molecules with alkali metal ion-exchanged ETS-10
}

\author{
Renjith S. Pillai, ${ }^{1, \#}$ Miguel Jorge, ${ }^{2}$ José R. B. Gomes ${ }^{1, *}$
}

${ }^{1}$ CICECO, Departamento de Química, Universidade de Aveiro, Campus Universitário de Santiago, P-3810-193 Aveiro, Portugal

${ }^{2}$ Department of Chemical and Process Engineering, University of Strathclyde, 75 Montrose Street, Glasgow G1 1XJ, United Kingdom

*Corresponding author. $\quad$ E-mail: irgomes@ua.pt Phone: +351 234401423

Fax: +351234401470

\#Present address: Chemical Sciences and Technology Division, CSIR-National Institute for Interdisciplinary Science and Technology (CSIRNIIST), Thiruvananthapuram-695019, India

Keywords: ETS-10; Sorption; Separation; Alkali metal ion; DFT calculations 


\begin{abstract}
In this paper, we present a systematic quantum-mechanical density functional theory (DFT) study of adsorption of small gas molecules in cation-exchanged Engelhard titanosilicate ETS-10 crystalline materials. Adsorbates with a range of polarities were considered, ranging from polar $\left(\mathrm{H}_{2} \mathrm{O}\right)$, quadrupolar $\left(\mathrm{CO}_{2}\right.$ and $\left.\mathrm{N}_{2}\right)$, to apolar $\left(\mathrm{CH}_{4}\right)$ atmospheric gases. Starting from the base-case of Na-ETS-10, other extra framework cations such as $\mathrm{Li}^{+}, \mathrm{K}^{+}, \mathrm{Rb}^{+}$and $\mathrm{Cs}^{+}$were considered. The DFT calculations were performed with the M06-L functional and were corrected for basis set superposition error with the counterpoise method in order to provide accurate and robust geometries and adsorption energies. For all adsorbates, the adsorption enthalpies decrease in the order $\mathrm{Li}^{+}>\mathrm{Na}^{+}>\mathrm{K}^{+}>\mathrm{Rb}^{+}>\mathrm{Cs}^{+}$, while adsorbate - cation interaction distances increase along the same order. For the two extreme cases, the enthalpies calculated at the M06-L/6-31++G** level of theory for $\mathrm{CH}_{4}, \mathrm{~N}_{2}, \mathrm{CO}_{2}$, and $\mathrm{H}_{2} \mathrm{O}$ interaction with $\mathrm{Li}^{+}\left(\mathrm{Cs}^{+}\right)$exchanged materials are -21.8 $(-1.7) \mathrm{kJ} \cdot \mathrm{mol}^{-1},-19.0(-10.7) \mathrm{kJ} \cdot \mathrm{mol}^{-1},-34.4(-21.3) \mathrm{kJ} \cdot \mathrm{mol}^{-1}$, and $-70.5(-36.1) \mathrm{kJ} \cdot \mathrm{mol}^{-1}$, respectively. Additionally, the calculated vibrational frequencies are found to be in quite good agreement with the characteristic vibrational modes of alkali metal cation-exchanged ETS-10 and also with the available experimental frequencies for $\mathrm{CH}_{4}, \mathrm{~N}_{2}, \mathrm{CO}_{2}$, and $\mathrm{H}_{2} \mathrm{O}$ interactions with alkali metal cations in the 12-membered channel of ETS- 10.
\end{abstract}




\section{Introduction}

The capture of carbon dioxide $\left(\mathrm{CO}_{2}\right)$ and methane $\left(\mathrm{CH}_{4}\right)$ gases will be inevitable for mankind in coming decades, especially due to increase of atmospheric temperature by global warming caused by emissions of greenhouse gases. The main sources for atmospheric $\mathrm{CO}_{2}$ and $\mathrm{CH}_{4}$ gases are coal-fired power plants and landfills. In the former case, $\mathrm{N}_{2}, \mathrm{CO}_{2}$ and $\mathrm{H}_{2} \mathrm{O}$ are the primary flue gases, while in the latter $\mathrm{H}_{2} \mathrm{O}$ is also found in large quantities. In both situations, several trace contaminants are also found such as nitrogen and sulfur oxides, their hydrates, compounds with more than one carbon atom, and hydrogen sulfide. ${ }^{1}$ An efficient and economic technology to separate $\mathrm{CO}_{2}$ from flue gases and landfill gases is of great priority. Among $\mathrm{CO}_{2}$ and $\mathrm{CH}_{4}$ capture techniques, including cryogenic distillation, chemical absorption and adsorptive separation, pressure swing adsorption (PSA) is a promising technique due to its proven success in many gas separation processes like $\mathrm{O}_{2}$ and $\mathrm{N}_{2}$ production from air, hydrogen recovery from hydrocarbon-rich gaseous streams, and paraffin-olefin separation ${ }^{2}$. In the design of adsorptionbased separation processes, the choice of adsorbent is a critical aspect. Titanosilicate molecular sieves showed promising capabilities for adsorption applications and, therefore, significant efforts have been made to understand how these adsorbents work and to optimize their potential for selective adsorption and separation of gases such as $\mathrm{CO}_{2}$ and $\mathrm{CH}_{4}{ }^{3}$

Among titanosilicate materials, Engelhard titanosilicate ETS-10 molecular sieves present interesting porous structures for selective adsorption. ${ }^{4-6}$ ETS-10 is a microporous zeotype material containing titanate chains originating in lines of corner-sharing $\mathrm{TiO}_{6}$ octahedra embedded in a silica framework. In this material, each $\mathrm{TiO}_{6}$ in the framework has an associated charge of -2 that is compensated by extra-framework exchangeable cations. ${ }^{5,7,8}$ The extra-framework cations arising during synthesis of ETS-10 (often $\mathrm{Na}^{+}$or $\mathrm{K}^{+}$) can be easily exchanged by other ions. The cation 
exchange necessarily modifies the adsorption capacities and selectivity of gases by ETS-10. The ability of cation exchange in ETS-10 can be exploited, for instance, to design appropriate adsorbents for temperature/pressure swing adsorption (TSA/PSA) techniques. ${ }^{9-14}$ In fact, ETS-10 has been suggested as an adsorbent for gas separation processes by several authors. ${ }^{910,12,15,16}$ For instance, Al-Baghli et al. ${ }^{9}$ and Anson et al. ${ }^{12}$ reported that $\mathrm{CH}_{4}$ and hydrocarbons can be captured employing the adsorptive separation technique, while Kuznicki et al. ${ }^{4,17}$ evidenced the good capacities of ETS-10 to separate $\mathrm{N}_{2}$ from landfill gas and air. ${ }^{17}$ Recently, Park et al. ${ }^{13}$ found that $\mathrm{CO}_{2}$ can be separated from its mixture with $\mathrm{N}_{2}$ using cation-exchanged ETS-10, even though they did not report the energetic differences of $\mathrm{CO}_{2}$ adsorption in various cation-exchanged ETS-10. It is important to note that the ability of ETS-10 to separate gases depends greatly on the difference in the interaction of the adsorbate with the extra-framework cations. Moreover, the enthalpy of adsorption is one of the decisive factors for designing an adsorbent in PSA/TSA technology. ${ }^{18}$

The adsorptive separation of $\mathrm{CO}_{2}$ from industrial flue gas and landfill gases, in particular, depends on interactions between the adsorbate molecules in the feed streams and the framework atoms, including the charge-balancing cations. The characterization and optimization of an adsorbent exclusively using experimental methods requires enormous time and it is also very expensive. Therefore, computational methods can be used as a complement to the more expensive experimental techniques for characterization of metal ion-exchanged ETS-10 and for understanding at the atomic level the interaction of gaseous molecules with these materials. The information gathered would be very important for understanding the gas separation process and for improving ETS-10 materials for this particular application.

Several authors, e.g. de Man and Sauer ${ }^{19}$, Ching et al. ${ }^{20}$, Bordiga et al. ${ }^{21}$, Zimmerman et al. ${ }^{22}$ and, Koç et al. ${ }^{23}$, calculated structural and electronic properties of ETS-10 materials using 
different computational methods combined with suitable cluster approaches for interpreting results obtained experimentally. Furthermore, vibrational frequencies for ETS-10 were calculated with density functional theory (DFT) and a single $-\mathrm{O}-\mathrm{Ti}-\mathrm{O}-$ chain model with three (3Ti) titanium atoms encapsulated in the supporting $\mathrm{SiO}_{2}$ framework by Guo et al. ${ }^{24}$ to aid the assignment of the bands from Raman spectroscopy. Recently, several DFT approaches together with Gaussian-type orbital basis sets were combined with a cluster model, based on a single -O-Ti-O- chain model with two (2Ti) titanium atoms encapsulated in a half portion of a 12-membered ring (MR), for calculating structural, electronic and vibrational properties for the interaction of five atmospheric gases (methane, carbon dioxide, nitrogen, hydrogen and water) with Na-ETS-10, ${ }^{25}$ The calculated adsorption enthalpies of these adsorbates in Na-ETS-10 were found to be in very good agreement with available experimental isosteric heats. ${ }^{25}$ Additionally, vibrational frequencies for methane, carbon dioxide, hydrogen and water interacting with the sodium ion in the 12-MR channel of the Na-ETS-10 cluster model were also found to compare well with vibrations determined experimentally (deviations below $30 \mathrm{~cm}^{-1}$ ).

Computational studies were also performed to explore the changes on the ETS-10 properties caused by different framework or extra-framework cations in its structure. For example, Waghmode et al. ${ }^{26}$ considered the Hartree-Fock method and different cluster models to study the catalytic properties of Pt particles incorporated in M-ETS-10 $\left(\mathrm{M}=\mathrm{Li}^{+}, \mathrm{Na}^{+}, \mathrm{K}^{+}, \mathrm{Rb}^{+}, \mathrm{Cs}^{+}\right.$, $(\mathrm{MgOH})^{+},(\mathrm{CaOH})^{+},(\mathrm{SrOH})^{+}$and $(\mathrm{BaOH})^{+}$ions). The calculations support an increasing basicity along the group on going from $\mathrm{Li}^{+}$to $\mathrm{Cs}^{+}$and from $\mathrm{Mg}^{2+}$ to $\mathrm{Ba}^{2+}$, which is consistent with an increase of activity in n-hexane aromatization in the same direction. The effects of substituting the framework $\mathrm{Ti}^{\mathrm{IV}}$ species in the $-\mathrm{O}-\mathrm{Ti}-\mathrm{O}-$ wires by $\mathrm{V}^{\mathrm{IV}}, \mathrm{V}^{\mathrm{V}}, \mathrm{Nb}^{\mathrm{V}}, \mathrm{Mo}^{\mathrm{V}}, \mathrm{Cr}^{\mathrm{III}}, \mathrm{Fe}^{\mathrm{III}}$ or $\mathrm{Cu}^{\mathrm{II}}$ on the photocatalytic properties of ETS-10 were analyzed by Shough et al. ${ }^{27}$. Their calculations using 
DFT and embedded cluster models predicted several transition metal combinations that improve the charge separation and decrease the band gap of the material, which are essential conditions for obtaining a more effective photocatalyst.

Despite the importance of ETS-10 in $\mathrm{CO}_{2}$ separation, the adsorption of $\mathrm{CO}_{2}, \mathrm{~N}_{2}, \mathrm{CH}_{4}$ and $\mathrm{H}_{2} \mathrm{O}$ with ETS-10 having various alkali metal cations was not studied thoroughly. The present study aims at providing an atomic level knowledge about $\mathrm{CH}_{4}, \mathrm{CO}_{2}, \mathrm{~N}_{2}$ and $\mathrm{H}_{2} \mathrm{O}$ in alkali metal cation-exchanged ETS-10. For that purpose, DFT approaches were used to study the interaction of molecules with a finite cluster model of ETS-10 having alkali metal cations (cf. $\mathrm{Li}^{+}, \mathrm{Na}^{+}, \mathrm{K}^{+}$, $\mathrm{Rb}^{+}$, and $\mathrm{Cs}^{+}$ions). It is thought that the DFT results for the interactions of $\mathrm{H}_{2} \mathrm{O}, \mathrm{H}_{2}, \mathrm{CH}_{4}, \mathrm{CO}_{2}$ and $\mathrm{N}_{2}$ in monovalent cation-exchanged ETS-10 cluster models will provide important insight into the effect of different ions on the adsorption mechanism, thus allowing for a more rational design of this class of adsorbents.

\section{Computational methods}

The density functional calculations were performed with the M06-L exchange-correlation functional ${ }^{28}$ as implemented in the Gaussian 09 code. $^{29}$ The atomic electronic densities of all atoms, with the exceptions of $\mathrm{Rb}$ and $\mathrm{Cs}$, were described with the 6-31G basis set, augmented with polarization functions, $6-31 \mathrm{G}(\mathrm{d}, \mathrm{p})$, or with polarization and diffuse functions, $6-31++\mathrm{G}(\mathrm{d}, \mathrm{p})$. The diffuse functions were only considered for the atoms in the gas molecule and in the central region of the ETS-10 cluster model, i.e. the alkali metal ions and the framework oxygen atoms neighboring the cations (atoms labeled: O1, O2, O3, O4, O5, O6, O7, $\mathrm{M}_{\mathrm{I}}, \mathrm{M}_{\mathrm{II}}, \mathrm{M}_{\mathrm{III}}$, and $\mathrm{M}_{\mathrm{IV}}$ in Figure 1a). In the case of Rb and Cs atoms, the LANL2DZ basis set was used to treat the valence 
electrons while the corresponding LANL2 pseudopotential was used for the core electrons. The M06-L functional is used in this work since in a recent comparative study on the performance of nine different DFT functionals to calculate the adsorption enthalpy of methane with a cluster model of Na-ETS-10, the M06-L approach was found to provide the best results. ${ }^{9,25}$ Additionally, the calculated enthalpies corresponding to the interactions of nitrogen and carbon dioxide with $\mathrm{Na}$ ETS-10 ${ }^{25}$ were in very good quantitative agreement with the available experimental isosteric heats. ${ }^{17,30}$ Similarly, very good adsorption energies and frequencies were obtained with the M06 family of functionals for other systems known to be challenging for standard DFT approaches. ${ }^{31-}$ 34

The same $2 \mathrm{Ti}$ cluster model used in Ref. ${ }^{25}$ to study the interaction of atmospheric gases was considered in this work (Figure 1a). The ETS-10 cluster model contains two Ti atoms within the $-\mathrm{O}-\mathrm{Ti}-\mathrm{O}-\mathrm{Ti}-\mathrm{O}-$ chain and a half portion of the 12-MR (12-member ring) with the extra framework cations $(\mathrm{M}=\mathrm{Li}, \mathrm{Na}, \mathrm{K}, \mathrm{Rb}$ and $\mathrm{Cs})$, and was cut out from the crystallographic cell of ETS-10 (Figure 1b). We focused on the 12MR site because the $\mathrm{Na}^{+}$cations in this site are the most mobile and therefore most prone to substitution by cation exchange processes, and also because the large size of the 12MR cages can accommodate the large ions (e.g. $\left.\mathrm{Cs}^{+}\right)$together with the adsorbate species. As common practice, the dangling bonds were terminated with hydrogen atoms (hydroxyl groups). The terminating $\mathrm{H}$ atoms were placed at the same bond angles and dihedral angles as the corresponding $\mathrm{Si}$ or $\mathrm{Ti}$ atoms in the extended crystal structure, and at a bond distance of $0.96 \AA$, which is a typical value for this type of materials. ${ }^{35}$ The initial positions of the cations (i.e., prior to the optimization procedure) employed to neutralize the system were taken from Grillo and Carraza, ${ }^{36}$ who used molecular simulation to analyze cation locations in ETS-10 and obtained good agreement with experimental data of Wang and Jacobson. ${ }^{37}$ These authors identified four 
different positions where cations are located (cf. sites I, II, III and IV in Figure 1). In a recent grand canonical Monte Carlo (GCMC) study of methane adsorption in Na-ETS-10 and Na-ETS-4 materials by Pillai et al., ${ }^{38}$ the cation distribution and mobility in these materials was analyzed at methane pressures between 0 and $100000 \mathrm{kPa}$. In the case of Na-ETS-10 and in the absence of methane, the simulations by Pillai et al. ${ }^{38}$ confirmed the presence of extra-framework cations at the same sites identified in Grillo and Carraza's work, ${ }^{36}$ e.g. I - IV. Furthermore, Pillai et al. ${ }^{38}$ found that the sodium cations also populate the stable positions at the 12-member rings but with associated high degrees of mobility when compared with cations at positions I - IV. The latter observations are in agreement with those from the canonical ensemble (NVT) Monte Carlo simulation study by Nalaparaju et al. ${ }^{11}$

(a)

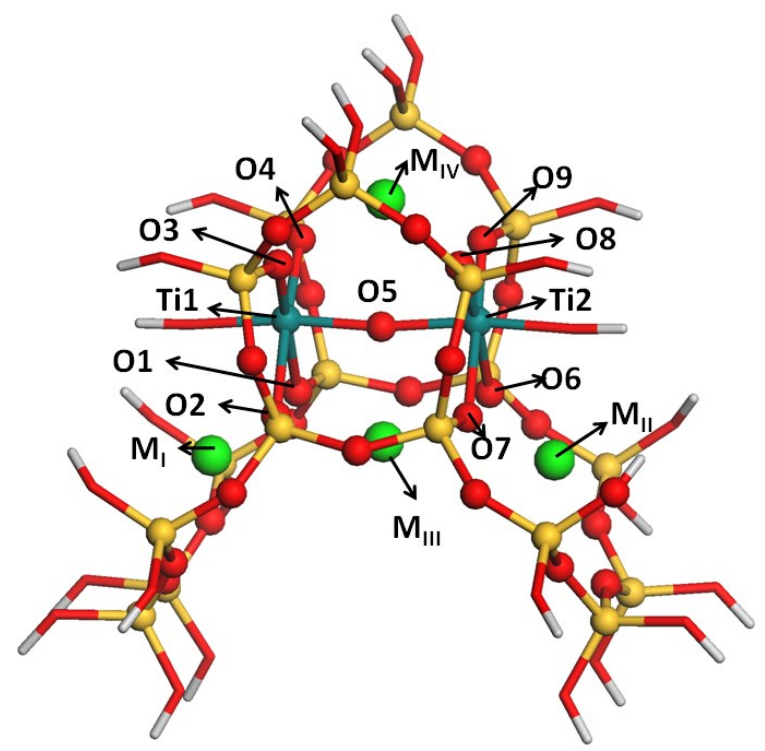

(b)

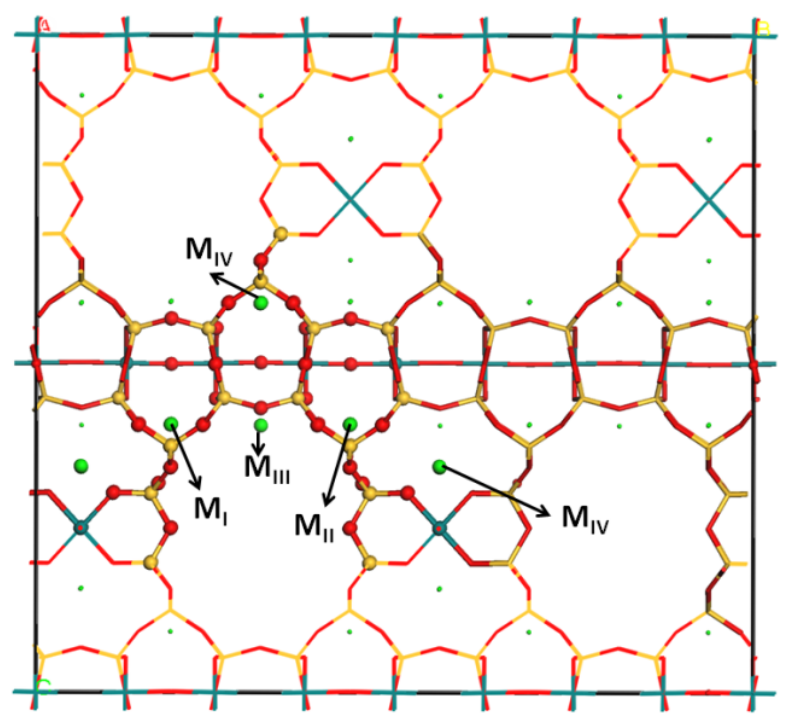

Figure 1. View of the cluster model (a) cut from the periodic structure of NaETS-10 (polymorph $\mathrm{B}$ from ref. ${ }^{5}$ ) shown in (b). The spheres in (a) represent atoms fully optimized in the DFT calculations, while sticks represent frozen atoms at their periodic positions. Note that terminal $\mathrm{Si}$ atoms were replaced by $\mathrm{H}$ in (a). Color code is: Bluish-green for $\mathrm{Ti}$, yellow for $\mathrm{Si}$, red for $\mathrm{O}$, green for cations $\left(\mathrm{M}^{+}\right)$and white for $\mathrm{H}$. 
In the sorbate-sorbent systems, the sorbate molecule was initially positioned close to the $\mathrm{M}_{\text {III }}$ cation, which is identified in Figure 1a. Notice that site III is located in the 12-MR channel and has less shielding from $\mathrm{O}$ atoms and, therefore, can establish relatively stronger interactions with guest molecules in the 12-MR channel as found previously for methane adsorption. ${ }^{38} \mathrm{The}^{+}$ cations in $\mathrm{M}_{\text {III }}$ positions were replaced by $\mathrm{Li}^{+}, \mathrm{K}^{+}, \mathrm{Rb}^{+}$and $\mathrm{Cs}^{+}$for studying the interaction of the remaining alkali metal ions with sorbates, because previous experimental ${ }^{39}$ and theoretical ${ }^{25}$ studies suggest a prominent formation of $\mathrm{M}_{\mathrm{III}}$ - Sorbate adducts in 12-MRs of ETS-10.

The cluster model has been chosen to describe the interactions of the sorbates with the cations as well as with the $-\mathrm{O}-\mathrm{Ti}-\mathrm{O}-$ chains in the large channels of ETS-10. Before calculation of adsorption energies, the structures of the different systems were fully optimized with the exception of the terminating hydroxyl groups in the Na-ETS-10 model, which were held fixed for a better representation of the rigid crystalline structure (Figure 1a). Note that a previous combined ${ }^{29}$ Si MAS NMR and Raman spectroscopy study by Pavel et al. ${ }^{40}$ analyzed the effect of ion exchange with different monovalent cations (e.g. $\mathrm{Na}^{+}, \mathrm{K}^{+}, \mathrm{Cs}^{+}$and $\mathrm{NH}_{4}^{+}$) on the ETS-10 local structure, concluding that only the latter ion induced important damages and that the structural changes caused by $\mathrm{K}^{+}$and $\mathrm{Cs}^{+}$could be reversed by sodium back-exchange. Thus, significant changes in the crystallographic positions of the remaining atoms in the Na-ETS-10 structure are not expected when the $\mathrm{Na}^{+}$ions are exchanged with $\mathrm{Li}^{+}, \mathrm{K}^{+}, \mathrm{Rb}^{+}$, or $\mathrm{Cs}^{+}$.

The electronic energy of adsorption, $\Delta E^{\mathrm{e}}$, was calculated as $\Delta E^{\mathrm{e}}=E_{\text {sorbate-adsorbent }}-E_{\text {adsorbent }}$ $-E_{\text {sorbate, }}$ where $E_{\text {adsorbent }}$ is the total energy of the isolated cluster model shown in Figure 1a, $E_{\text {sorbate }}$ is the total energy in vacuum of the sorbate (e.g. $\mathrm{N}_{2}, \mathrm{CO}_{2}, \mathrm{CH}_{4}$ or $\mathrm{H}_{2} \mathrm{O}$ ) and $E_{\text {sorbate-adsorbent }}$ is the total energy of the system, with the sorbate interacting with the cluster model. Thus, in the present notation, negative values for the adsorption energy mean favorable adsorption. Energies of 
adsorption corrected with the zero-point energy, $\Delta E^{0}$, and enthalpies of adsorption at $T=298.15 \mathrm{~K}$, $\Delta H^{298.15 \mathrm{~K}}$, were also obtained in this work by the inclusion of the zero-point energy or the thermal corrections, respectively, taken from the calculation of vibrational frequencies, which were also used to characterize all the structures as true minima on the potential energy surface. The geometries, the energies and the enthalpies of adsorption include the basis set superposition error (BSSE) corrections calculated with the counterpoise method. ${ }^{41}$ The BSSE corrections were shown to be essential to obtain energies in good agreement with experiment. ${ }^{25,42}$

Generally, calculated frequencies overestimate the experimentally observed values. Therefore, it is common practice to correct the computed frequencies upon the utilization of a scaling factor. ${ }^{43}$ Herewith, the calculated vibrational frequencies with values above $1000 \mathrm{~cm}^{-1}$ were scaled with an optimal scaling factor of 0.949 obtained in our previous work,${ }^{25}$ while the frequencies with values below $1000 \mathrm{~cm}^{-1}$ were left unscaled. This strategy was found previously ${ }^{25,42}$ to correct very well the frequencies computed for the interaction of several different adsorbates with the same Na-ETS-10 molecular model used in the present work.

\section{Results and Discussion}

\subsection{Structure of the alkali metal ion-exchanged ETS-10}

In Table 1, we report selected geometrical parameters for the optimized structure of the alkali metal ion-exchanged ETS-10 cluster model. The position of the alkali metal cations at the large 12-MR channel (Figure 1) are influenced by the local geometry of the ETS-10 framework. According to single crystal data of Wang and Jacobson in Na-ETS- $10,{ }^{37}$ the $\mathrm{M}_{\mathrm{III}}$ cation is coordinated to five oxygen atoms while other cations $\mathrm{M}_{\mathrm{I}}, \mathrm{M}_{\mathrm{II}}$ and $\mathrm{M}_{\mathrm{IV}}$ are coordinated to eight 
oxygen atoms. The range of distances calculated in our previous work ${ }^{25}$ with the M06-L functional and the 2Ti model shown in Figure 1a is similar to that reported by Zimmerman et al. ${ }^{22}$ using a 5Ti model and the ONIOM (DFT:MM) approach. Additionally, the distances calculated in these two studies are in satisfactory agreement with the single crystal X-ray diffraction data taken from Wang and Jacobson. ${ }^{37}$ As expected, not only the ETS-10 framework atomic distances are similar for all alkali metal ion-exchanged ETS-10 but also the distances between the cation and the framework oxygen, $\mathrm{O} 5$, increase upon increasing the size of the cation. The smaller, $\mathrm{Li}$, and bigger, Cs, cations are $1.88 \AA$ and $3.3 \AA$, respectively, distant from the nearest framework oxygen, O5. It is also evident that the Ti1-O5-Ti2 angle is reduced from $173.9^{\circ}$ to $164.5^{\circ}$ to better accommodate the cations as their size is increased.

Table 1. Comparison of selected geometrical parameters calculated for the bare M-ETS-10 cluster model.

\begin{tabular}{|c|c|c|c|c|c|}
\hline \multirow{2}{*}{ Adsorbent } & \multicolumn{5}{|c|}{ Parameter $^{\mathbf{a}}$} \\
\cline { 2 - 6 } & Tix-Oy & Tix-O5 & $\mathrm{M}_{\text {III }}{ }^{+}-\mathrm{O} z$ & $\mathrm{M}_{\text {III }}{ }^{+}-\mathrm{O} 5$ & Ti1-O5-Ti2 \\
\hline Li-3Na-ETS-10 & $1.90-2.16$ & 1.87 & $2.09-2.38$ & 1.88 & 173.9 \\
\hline Na-3Na-ETS-10 & $1.91-2.12$ & 1.86 & 2.42 & 2.25 & 172.3 \\
\hline K-3Na-ETS-10 & $1.93-2.10$ & 1.86 & 2.74 & 2.70 & 167.4 \\
\hline Rb-3Na-ETS-10 & $1.93-2.09$ & 1.86 & 2.94 & 2.99 & 166.0 \\
\hline Cs-3Na-ETS-10 & $1.94-2.09$ & 1.86 & 3.18 & 3.30 & 164.5 \\
\hline
\end{tabular}

${ }^{a}$ Atomic labeling in Figure 1 with $x=1$ or $2, y=1-4$ or $6-9, z=1,2,6$ or 7 ; distances in $\AA$ and angles in degrees.

The vibrational frequencies calculated at the M06-L level of theory for the framework region of alkali metal cation-exchanged ETS-10 are compared in Figure 2. A list with the most intense vibrations is provided in the Supporting Information (Table S1), which are compared with the 
infrared bands obtained experimentally. ${ }^{44-47}$ The spectra in Figure 2 show the characteristic peaks described for ETS-10 materials, namely, the very intense band at $\sim 1100 \mathrm{~cm}^{-1}$ (Si-O stretching; shoulders at larger and smaller wavenumbers in all systems with the exception of Li-3Na-ETS10), and smaller but intense bands at $\sim 1000 \mathrm{~cm}^{-1}$ (SiO-Ti-OSi rocking), at $740 / 710 \mathrm{~cm}^{-1}$ (Ti-OTi stretching), $460 \mathrm{~cm}^{-1}$ (SiO-Ti-OSi wagging) and $360 \mathrm{~cm}^{-1}$ (Ti-O-Ti stretching), approximately. The vibrational frequencies calculated for alkali metal cation-exchanged ETS-10 are in good agreement with the experimental peaks as reported in Table S1.

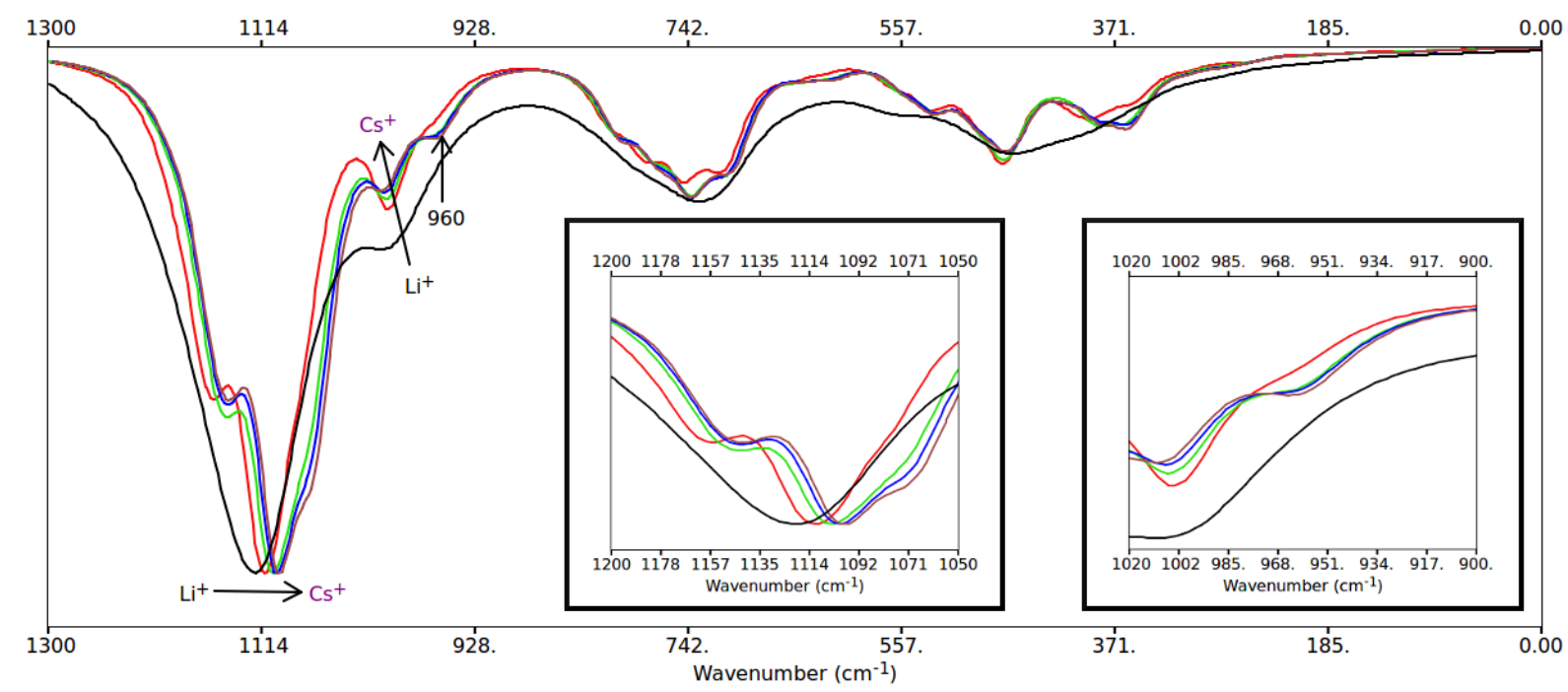

Figure 2. Calculated infrared spectra of NaETS-10 and alkali metal ion-exchanged NaETS-10. Color code is: Li-3Na-ETS-10 (black), Na-3Na-ETS-10 (red), K-3Na-ETS-10 (green), Rb-3NaETS-10 (blue) and Cs-3Na-ETS-10 (purple). Inserted images are magnifications of selected regions. Spectra were plotted with Gabedit. ${ }^{48}$ Vibrations are unscaled and were normalized with respect to the intensity of the most prominent vibration. 
A vibration at $\sim 960 \mathrm{~cm}^{-1}$ is present in all the calculated spectra but in Li-3Na-ETS-10 and Na3Na-ETS-10 the intensity of the vibration is smaller than in the other materials. The intensity of this vibration increases from $\mathrm{Li}^{+}$(143) to $\mathrm{Na}^{+}(283)$ to $\mathrm{K}^{+}$(530) to $\mathrm{Rb}^{+}$(582) to ${ }^{+} \mathrm{Cs}$ (635). The vibration at $\sim 960 \mathrm{~cm}^{-1}$, which is characteristic of the framework of zeolites TS-1 and Ti- $\beta$, has been observed ${ }^{45}$ in some experimental spectra of ETS-10 materials but was absent ${ }^{46}$ in other works. We have inspected visually this vibration and it is related with the $\mathrm{Si}-\mathrm{O}(-\mathrm{Ti})$ stretching, i.e., with bond between silicon and oxygen atoms labelled 1-4 or 5-9 in Figure 1. Therefore, based on the calculated data, it is possible to hypothesize that the experimental observation of the vibration at $\sim 960 \mathrm{~cm}^{-1}$ can be associated to materials with higher percentages of larger ions at position $\mathrm{M}_{\mathrm{III}}$ (Figure 1). Note that the experimental samples of the ETS-10 materials contain simultaneously sodium and potassium ions.

As it is highlighted in Figure 1, the calculated vibrational wavenumbers of the most intense band $\left(\sim 1100 \mathrm{~cm}^{-1}\right)$ decrease from $\mathrm{Li}^{+}$to $\mathrm{Cs}^{+}$while an opposite effect is seen for the vibration at $\sim 1000$ $\mathrm{cm}^{-1}$. The shift of these peaks with the size of the ions agrees with the observations by Waghmode et al. ${ }^{47}$ who observed a slight increase from $1058 \mathrm{~cm}^{-1}$ to $1065 \mathrm{~cm}^{-1}$ on going from $\mathrm{Li}$ - to Csexchanged ETS-10 materials.

\subsection{Adsorption of atmospheric gases in alkali metal ion-exchanged ETS-10}

In our previous study, DFT calculations employing the M06-L functional on the Na-ETS-10 cluster model ${ }^{25,42}$ yielded an adsorption enthalpy for the apolar molecule, methane, in very good agreement with available experimental results, in the range between -20.8 and $-23.3 \mathrm{~kJ} \cdot \mathrm{mol}^{-1}$, which were deduced from the fit of Toth, unilan or virial three-constants models to the adsorption data obtained with volumetric systems at temperatures around $T=298.15 \mathrm{~K} \cdot{ }^{9,30}$ Furthermore, the 
calculated enthalpies for nitrogen and carbon dioxide are $-21.5 \mathrm{~kJ} \cdot \mathrm{mol}^{-1}$ and $-35.3 \mathrm{~kJ} \cdot \mathrm{mol}^{-1}$, respectively, ${ }^{25}$ which are also in reasonable agreement with available experimental isosteric heats. ${ }^{17,30}$ Additionally, vibrational frequencies for methane, carbon dioxide, hydrogen and water interacting with the Na-ETS-10 cluster were also found to compare well with vibrations determined experimentally $\left(\Delta<30 \mathrm{~cm}^{-1}\right)$. These results demonstrate the reliability of the adopted DFT approach, and in the following we apply it to elucidate the interaction of small gas molecules with cation-exchanged ETS-10.

\subsubsection{Adsorption of methane in alkali metal ion-exchanged ETS-10}

The energies and enthalpies of adsorption of methane with alkali metal ion-exchanged ETS-10 at $T=298.15 \mathrm{~K}$ calculated at the M06-L level of theory, incorporating BSSE corrections, are given in Table 2 . The calculated methane enthalpy shows that the interaction between the cation and methane molecule weakens upon increasing the size of the cation in the 12MRs, i.e, the Liexchanged ETS-10 has the highest enthalpy for methane in the series of all alkali metal ionexchanged ETS-10. The optimized configurations for methane in ion-exchanged ETS-10 are shown in Figure S2, in which it can be seen that the distance between the alkali metal ion and the carbon atom of methane, $\mathrm{d}\left(\mathrm{M}_{\mathrm{III}}{ }^{+} \cdots \mathrm{C}\right)$, increases on increasing the cation size, in the reverse order

of the calculated enthalpies. The calculated vibrational frequencies indicate a red shift in $\mathrm{C}-\mathrm{H}$ stretching frequency on exchanging the alkali ions from $\mathrm{Li}^{+}$to ${ }^{+} \mathrm{Cs}$ (Table 3). The enthalpies and vibrational frequencies of methane adsorption in alkali metal ion-exchanged ETS-10 reveal that the size of the extra-framework cation in ETS-10 is a crucial deciding factor for methane adsorption capability in ETS-10. 
Table 2. Calculated energies and enthalpies of adsorption, with BSSE corrections, for methane in alkali metal ion exchanged ETS-10. All values in $\mathrm{kJ} \cdot \mathrm{mol}^{-1}$.

\begin{tabular}{|c|c|c|c|}
\hline Adsorbent & $\boldsymbol{\Delta} \boldsymbol{E}^{\mathbf{e}}$ & $\boldsymbol{\Delta} \boldsymbol{E}^{\mathbf{0}}$ & $\boldsymbol{\Delta} \boldsymbol{H}^{\mathbf{2 9 8 . 1 5} \mathbf{K}}$ \\
\hline Li-3Na-ETS10 & -29.6 & -22.2 & -21.8 \\
\hline Na-3Na-ETS10 a & -27.4 & -20.2 & -20.8 \\
\hline K-3Na-ETS10 & -15.2 & -6.7 & -7.7 \\
\hline Rb-3Na-ETS10 & -10.8 & -3.2 & -3.7 \\
\hline Cs-3Na-ETS10 & -7.3 & -2.6 & -1.7 \\
\hline
\end{tabular}

${ }^{\text {a }}$ Experimental isosteric heats ${ }^{9,30}$ are in the range $-20.8 \mathrm{~kJ} \cdot \mathrm{mol}^{-1}$ to $-23.3 \mathrm{~kJ} \cdot \mathrm{mol}^{-1}$. Using the data in these works and the Clausius-Clapeyron equation we obtained isosteric heats between -21.3 $\mathrm{kJ} \cdot \mathrm{mol}^{-1}$ and $-23.3 \mathrm{~kJ} \cdot \mathrm{mol}^{-1}$ for methane loadings between $0.600 \mathrm{~mol} \cdot \mathrm{kg}^{-1}$ and $0.068 \mathrm{~mol} \cdot \mathrm{kg}^{-1}$ (Figure S5 in the Supporting Information).

Table 3. Comparison of relevant calculated and experimental vibrational frequencies $\left(\mathrm{cm}^{-1}\right)$ for methane in alkali metal ion exchanged ETS-10. ${ }^{\text {a }}$

\begin{tabular}{|c|c|c|c|}
\hline \multirow{2}{*}{ Adsorbent } & \multirow{2}{*}{ Calculated } & \multicolumn{2}{|c|}{ Experimental } \\
\hline & & Bands & Ref. \\
\hline Li-3Na-ETS10 & $\begin{array}{c}2874\left(v_{\mathrm{C}-\mathrm{H}}\right) \\
1265\left(\delta_{\mathrm{H}-\mathrm{C}-\mathrm{H}}\right)\end{array}$ & & \\
\hline Na-3Na-ETS10 & $\begin{array}{c}2876\left(v_{\mathrm{C}-\mathrm{H}}\right), \\
1250\left(\delta_{\mathrm{H}-\mathrm{C}-\mathrm{H}}\right)\end{array}$ & $\mathbf{2 8 8 5}, 2893,2900\left(v_{\mathrm{C}-\mathrm{H}}\right)$ & 49 \\
\hline $\mathrm{K}-3 \mathrm{Na}-\mathrm{ETS} 10$ & $\begin{array}{c}2878\left(v_{\mathrm{C}-\mathrm{H}}\right) \\
1250\left(\delta_{\mathrm{H}-\mathrm{C}-\mathrm{H}}\right)\end{array}$ & & \\
\hline Rb-3Na-ETS10 & $\begin{array}{c}2895\left(v_{\mathrm{C}-\mathrm{H}}\right) \\
1250\left(\delta_{\mathrm{H}-\mathrm{C}-\mathrm{H}}\right)\end{array}$ & & \\
\hline Cs-3Na-ETS10 & $\begin{array}{c}2897\left(v_{\mathrm{C}-\mathrm{H}}\right) \\
1261\left(\delta_{\mathrm{H}-\mathrm{C}-\mathrm{H}}\right)\end{array}$ & & \\
\hline
\end{tabular}

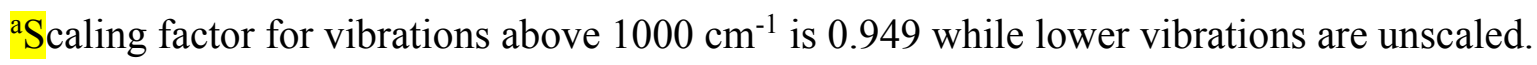




\subsubsection{Adsorption of nitrogen in alkali metal ion-exchanged ETS-10.}

Figure S2 shows the optimized configurations of $\mathrm{N}_{2}$ interactions on alkali metal ionexchanged ETS-10, while relevant interatomic distances are provided in Table S3. From the data in Table $\mathrm{S} 3$, it is found that the $\mathrm{N}_{2}$ molecule is not affecting too much the position of the $\mathrm{M}_{\text {III }}$ ion, which despite being less coordinated to the framework oxygen atoms than $\mathrm{M}_{\mathrm{I}}, \mathrm{M}_{\mathrm{II}}$ and $\mathrm{M}_{\mathrm{IV}}$, moves only slightly from its original location in the bare alkali metal ion-exchanged ETS-10 model (cf. Table 1). However, the adsorption enthalpies calculated for $\mathrm{N}_{2}$ in alkali metal ion-exchanged ETS10 (see Table 4) span a range of values between $-10.7 \mathrm{~kJ} \cdot \mathrm{mol}^{-1}(\mathrm{Cs}-3 \mathrm{Na}-\mathrm{ETS}-10)$ and $-21.5 \mathrm{~kJ} \cdot \mathrm{mol}^{-}$ ${ }^{1}$ (Na-3Na-ETS-10), i.e., the adsorption energy for $\mathrm{N}_{2}$ is decreasing upon increasing the cation size. However, Li-3Na-ETS-10 is an exception to the trend, with an enthalpy of adsorption that is slightly less negative than for Na-ETS-10. In case of $\mathrm{N}_{2}$, a red shift in the vibrational frequencies is also observed upon exchanging alkali ions from $\mathrm{Li}^{+}$to ${ }^{+} \mathrm{Cs}$ (Table 5).

Table 4. Calculated energies and enthalpies of adsorption, with BSSE corrections, for nitrogen in alkali metal ion exchanged ETS-10. All values in $\mathrm{kJ} \cdot \mathrm{mol}^{-1}$.

\begin{tabular}{|c|c|c|c|}
\hline Adsorbent & $\boldsymbol{\Delta E}^{\mathbf{e}}$ & $\boldsymbol{\Delta}^{\mathbf{0}}$ & $\boldsymbol{\Delta}^{\mathbf{2 9 8 . 1 5} \mathbf{K}}$ \\
\hline Li-3Na-ETS10 & -22.7 & -19.6 & -19.0 \\
\hline Na-3Na-ETS10 ${ }^{\text {a }}$ & -22.8 & -20.8 & -21.5 \\
\hline K-3Na-ETS10 & -17.7 & -13.9 & -12.7 \\
\hline Rb-3Na-ETS10 & -16.4 & -11.7 & -11.3 \\
\hline Cs-3Na-ETS10 & -16.3 & -11.3 & -10.7 \\
\hline
\end{tabular}

${ }^{a}$ Experimental isosteric heat ${ }^{17}$ determined from adsorption of air is $-22.8 \mathrm{~kJ} \cdot \mathrm{mol}^{-1}$. 
Table 5. Comparison of relevant calculated and experimental vibrational frequencies $\left(\mathrm{cm}^{-1}\right)$ for nitrogen in Na-ETS-10. ${ }^{\mathrm{a}}$

\begin{tabular}{|c|c|c|c|}
\hline \multirow{2}{*}{ Sorbate } & Calculated & \multicolumn{2}{|c|}{ Experimental } \\
\cline { 3 - 4 } & $2299\left(v_{\mathrm{N}-\mathrm{N}}\right)$ & Bands & Ref. \\
\hline Li-3Na-ETS10 & $2307\left(v_{\mathrm{N}-\mathrm{N}}\right)$ & & \\
\hline $\mathrm{Na}-3 \mathrm{Na}-E T S 10$ & $2313\left(v_{\mathrm{N}-\mathrm{N}}\right)$ & & 39 \\
\hline $\mathrm{K}-3 \mathrm{Na}-\mathrm{ETS} 10$ & $2317\left(v_{\mathrm{N}-\mathrm{N}}\right)$ & & \\
\hline $\mathrm{Rb}-3 \mathrm{Na}-\mathrm{ETS} 10$ & $2320\left(v_{\mathrm{N}-\mathrm{N}}\right)$ & & \\
\hline Cs-3Na-ETS10 & & & \\
\hline
\end{tabular}

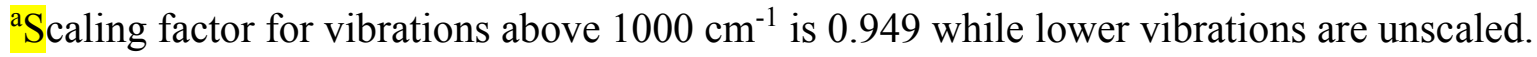

\subsubsection{Adsorption of carbon dioxide in alkali metal ion-exchanged ETS-10.}

In a previous study, ${ }^{25}$ the calculations for $\mathrm{CO}_{2}$ adsorption in alkali metal ion-exchanged ETS10 were performed with two different types of basis sets, $6-31 \mathrm{G}^{* *}$ and $6-31++\mathrm{G}^{* *}$. As discussed in that work, the calculated M06-L enthalpies of adsorption at $T=298.15 \mathrm{~K}$ for carbon dioxide in Na-ETS-10, i.e. $-35.3 \mathrm{~kJ} \cdot \mathrm{mol}^{-1}$ or $-39.0 \mathrm{~kJ} \cdot \mathrm{mol}^{-1}$ depending on the consideration of diffuse functions for the sodium ion neighboring atoms (Figure 1), are somewhat lower than an experimental value $\left(-42.1 \mathrm{~kJ} \cdot \mathrm{mol}^{-1}\right)$ at a higher temperature, ${ }^{30}$ but they are close to another theoretical estimate $\left(-37 \mathrm{~kJ} \cdot \mathrm{mol}^{-1}\right)$, from classical GCMC simulations at the same temperature reported by Gallo et al. ${ }^{50}$ In this work, all calculations were performed with diffuse functions in the adsorbate, in the alkali metal ions and in the framework oxygen atoms neighboring the cations.

As found for methane and nitrogen, the $\mathrm{CO}_{2}$ molecule is interacting with the Li to Cs alkali metal ions at increasing distances along the series (from $2.40 \AA$ to $3.11 \AA$; Table S4). The configurations optimized for the $\mathrm{CO}_{2}$ molecule interacting with the alkali metal ion-exchanged 
ETS-10 model are depicted in Figure S3. In accordance with $\mathrm{N}_{2}$ interaction on ETS-10, the initial position of the alkali metal ion in the framework does not change significantly upon $\mathrm{CO}_{2}$ adsorption. This small variation is quite interesting, since the adsorption enthalpies calculated for $\mathrm{CO}_{2}$ in alkali metal ion-exchanged ETS-10 (see Table 6) span a significant range of values between $-21.3 \mathrm{~kJ} \cdot \mathrm{mol}^{-1}$ (Cs-3Na-ETS-10) and $-35.1 \mathrm{~kJ} \cdot \mathrm{mol}^{-1}$ (Na-3Na-ETS-10). The adsorption energy for $\mathrm{CO}_{2}$ in alkali metal ion-exchanged ETS-10 is decreasing upon increasing the cation size. The trend is the same as observed for the apolar molecule methane, but the adsorption energies for the latter are much less favorable and they seem to be much more affected by a change in the cation - the enthalpies range from -1.7 to $-21.8 \mathrm{~kJ} \cdot \mathrm{mol}^{-1}$ for methane (Table 2). As found for the case of nitrogen adsorption, $\mathrm{Li}-3 \mathrm{Na}-\mathrm{ETS}-10$ is an exception to the trend in the case of $\mathrm{CO}_{2}$, with an enthalpy of adsorption that is slightly lower than for Na-ETS-10. The largest Cs cation has the lowest enthalpy of adsorption; nevertheless, Cs does not cause the largest displacement from the bare geometrical position (the $\mathrm{Cs}-\mathrm{O} 5$ distance in the case of $\mathrm{CO}_{2}$ adsorption, i.e., $3.30 \AA$, is slightly increased by $\sim 0.03 \AA$ ). The selected vibrational frequencies calculated at M06-L/6-31++G** for $\mathrm{CO}_{2}$ in alkali metal ion-exchanged ETS-10 are given in Table 7, which shows a red shift in $\mathrm{O}-\mathrm{C}-$ O bending frequency on exchanging Li to Cs.

Table 6. Calculated energies and enthalpies of adsorption, with BSSE corrections, for carbon dioxide in alkali metal ion exchanged ETS-10. All values in $\mathrm{kJ} \cdot \mathrm{mol}^{-1}$.

\begin{tabular}{|c|c|c|c|}
\hline Adsorbent & $\boldsymbol{\Delta} \boldsymbol{E}^{\mathbf{e}}$ & $\boldsymbol{\Delta} \boldsymbol{E}^{\mathbf{0}}$ & $\boldsymbol{\Delta} \boldsymbol{H}^{\mathbf{2 9 8 . 1 5} \mathbf{K}}$ \\
\hline Li-3Na-ETS10 & -36.8 & -36.0 & -34.4 \\
\hline Na-3Na-ETS10 & -39.5 & -36.4 & -35.3 \\
\hline K-3Na-ETS10 & -33.8 & -30.9 & -29.7 \\
\hline
\end{tabular}




\begin{tabular}{|c|c|c|c|}
\hline $\mathrm{Rb}-3 \mathrm{Na}-\mathrm{ETS} 10$ & -33.3 & -30.9 & -29.8 \\
\hline $\mathrm{Cs}-3 \mathrm{Na}-\mathrm{ETS} 10$ & -27.6 & -20.5 & -21.3 \\
\hline
\end{tabular}

${ }^{\text {a }}$ Experimental isosteric heat ${ }^{30}$ is $-42.1 \mathrm{~kJ} \cdot \mathrm{mol}^{-1}$.

Table 7. Comparison of relevant calculated and experimental vibrational frequencies $\left(\mathrm{cm}^{-1}\right)$ for $\mathrm{CO}_{2}$ in ion-exchanged ETS-10. ${ }^{\mathrm{a}}$

\begin{tabular}{|c|c|c|c|}
\hline \multirow{2}{*}{ Sorbate } & \multirow{2}{*}{ Calculated } & \multicolumn{2}{|c|}{ Experimental } \\
\hline & & Bands & Ref. \\
\hline Li-3Na-ETS 10 & $\begin{array}{c}2354\left(v_{\mathrm{O}-\mathrm{C}-\mathrm{O}}\right), \\
1307\left(v_{\mathrm{O}-\mathrm{C}-\mathrm{O}}\right), \\
1152\left(v_{\mathrm{O}-\mathrm{C}-\mathrm{O}}\right), \\
665\left(\delta_{\mathrm{O}-\mathrm{C}-\mathrm{O}}\right)\end{array}$ & 2356 & 47 \\
\hline Na-3Na-ETS10 & $\begin{array}{c}2359\left(v_{\mathrm{O}-\mathrm{C}-\mathrm{O}}\right), \\
1309\left(v_{\mathrm{O}-\mathrm{C}-\mathrm{O}}\right), \\
1146\left(v_{\mathrm{O}-\mathrm{C}-\mathrm{O}}\right), \\
665\left(\delta_{\mathrm{O}-\mathrm{C}-\mathrm{O}}\right)\end{array}$ & $\begin{array}{c}2353\left(v_{\mathrm{O}-\mathrm{C}-\mathrm{O}}\right) \\
1690,1365 \\
1381,1274\end{array}$ & 51 \\
\hline K-3Na-ETS10 & $\begin{array}{c}2363\left(v_{\mathrm{O}-\mathrm{C}-\mathrm{O}}\right), \\
1312\left(v_{\mathrm{O}-\mathrm{C}-\mathrm{O}}\right), \\
1138\left(v_{\mathrm{O}-\mathrm{C}-\mathrm{O}}\right), \\
665\left(\delta_{\mathrm{O}-\mathrm{C}-\mathrm{O}}\right)\end{array}$ & $2347^{\mathrm{b}}$ & 47 \\
\hline $\mathrm{Rb}-3 \mathrm{Na}-\mathrm{ETS} 10$ & $\begin{array}{c}2367\left(v_{\mathrm{O}-\mathrm{C}-\mathrm{O}}\right), \\
1312\left(v_{\mathrm{O}-\mathrm{C}-\mathrm{O}}\right), \\
1138\left(v_{\mathrm{O}-\mathrm{C}-\mathrm{O}}\right), \\
665\left(\delta_{\mathrm{O}-\mathrm{C}-\mathrm{O}}\right)\end{array}$ & $2345^{\mathrm{b}}$ & 47 \\
\hline Cs-3Na-ETS10 & $\begin{array}{c}2377\left(v_{\mathrm{O}-\mathrm{C}-\mathrm{O}}\right), \\
1315\left(\mathrm{v}_{\mathrm{O}-\mathrm{C}-\mathrm{O}}\right), \\
1136\left(\mathrm{v}_{\mathrm{O}-\mathrm{C}-\mathrm{O}}\right), \\
665\left(\delta_{\mathrm{O}-\mathrm{C}-\mathrm{O}}\right)\end{array}$ & 2342 & 47 \\
\hline
\end{tabular}

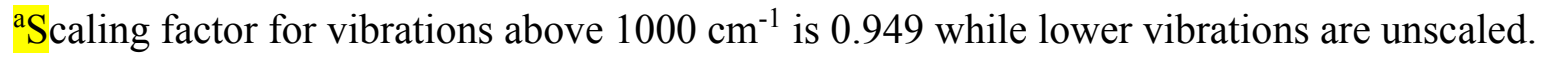
${ }^{\mathrm{b}}$ Engauge digitizer (http://digitizer.sourceforge.net) was used to read experimental data. 


\subsubsection{Adsorption of water in alkali metal ion-exchanged ETS-10}

The optimization of the geometries and calculation of the energies and enthalpies corresponding to the interactions of $\mathrm{H}_{2} \mathrm{O}$ with alkali metal ion-exchanged ETS-10 were also calculated at M06-L/6-31++G** level and the optimized configurations are shown in Figure S4. The $\mathrm{H}_{2} \mathrm{O}$ molecule is interacting with the $\mathrm{Li}^{+}, \mathrm{Na}^{+}, \mathrm{K}^{+}, \mathrm{Rb}^{+}$, and $\mathrm{Cs}^{+}$alkali metal ions (cf. Figure 1) at increasing distances ranging from $2.13 \AA$ to $3.14 \AA$ (Table S5). As with all other gases, $\mathrm{H}_{2} \mathrm{O}$ also is not affecting too much the position of the $\mathrm{M}_{\mathrm{III}}$ ion. The adsorption enthalpies calculated for $\mathrm{H}_{2} \mathrm{O}$ in alkali metal ion-exchanged ETS-10 (see Table 8) span a range of values between -36.1 $\mathrm{kJ} \cdot \mathrm{mol}^{-1}$ (Cs-3Na-ETS-10) and $-70.5 \mathrm{~kJ} \cdot \mathrm{mol}^{-1}$ (Li-3Na-ETS-10). As expected, the adsorption energy for $\mathrm{H}_{2} \mathrm{O}$ is in the reverse order of the alkali metal ion size. The selected vibrational frequencies for water interaction in alkali metal exchanged ETS-10 are given in Table 9. The results indicate a red shift in $\mathrm{O}-\mathrm{H}$ stretching frequency on exchanging $\mathrm{Li}$ to $\mathrm{Cs}$.

Table 8. Calculated energies and enthalpies of adsorption, with BSSE corrections, for water in alkali metal ion exchanged ETS-10. All values in $\mathrm{kJ} \cdot \mathrm{mol}^{-1}$.

\begin{tabular}{|c|c|c|c|}
\hline Adsorbent & $\boldsymbol{\Delta} \boldsymbol{E}^{\mathbf{e}}$ & $\boldsymbol{\Delta} \boldsymbol{E}^{\mathbf{0}}$ & $\boldsymbol{\Delta} \boldsymbol{H}^{\mathbf{2 9 8 . 1 5} \mathbf{~}}$ \\
\hline Li-3Na-ETS10 & -76.5 & -66.8 & -70.5 \\
\hline Na-3Na-ETS10 & -66.7 & -59.1 & -60.6 \\
\hline K-3Na-ETS10 & -59.1 & -50.0 & -52.1 \\
\hline Rb-3Na-ETS10 & -59.0 & -49.6 & -51.9 \\
\hline Cs-3Na-ETS10 & -42.3 & -35.1 & -36.1 \\
\hline
\end{tabular}


Table 9. Comparison of relevant calculated and experimental vibrational frequencies $\left(\mathrm{cm}^{-1}\right)$ for water adsorption in M-ETS-10. ${ }^{\text {a }}$

\begin{tabular}{|c|c|c|c|}
\hline \multirow{3}{*}{ Sorbate } & Calculated & \multicolumn{2}{|c|}{ Experimental } \\
\cline { 2 - 4 } Li-3Na-ETS10 & $3717\left(v_{\mathrm{O}-\mathrm{H}}\right)$ & Bands & Ref. \\
& $3480\left(v_{\mathrm{O}-\mathrm{H}}\right)$ & & \\
& $1573\left(\delta_{\mathrm{H}-\mathrm{O}-\mathrm{H}}\right)$ & & \\
Na-3Na-ETS10 & $3731\left(v_{\mathrm{O}-\mathrm{H}}\right)$, & $3670\left(v_{\mathrm{O}-\mathrm{H}}\right)$, & \\
& $3524\left(v_{\mathrm{O}-\mathrm{H}}\right)$ & $3580\left(v_{\mathrm{O}-\mathrm{H}}\right)$, & \\
& $1611\left(\delta_{\mathrm{H}-\mathrm{O}-\mathrm{H}}\right)$ & & \\
& $3749\left(v_{\mathrm{O}-\mathrm{H}}\right)$ & & \\
K-3Na-ETS10 & $3528\left(v_{\mathrm{O}-\mathrm{H}}\right)$ & & \\
& $1584\left(\delta_{\mathrm{H}-\mathrm{O}-\mathrm{H}-\mathrm{O}-\mathrm{H})}\right.$ & \\
\hline \multirow{3}{*}{ Rb-3Na-ETS10 } & $3760\left(v_{\mathrm{O}-\mathrm{H}}\right)$ & & \\
& $3563\left(v_{\mathrm{O}-\mathrm{H}}\right)$ & & \\
\hline \multirow{3}{*}{ Cs-3Na-ETS10 } & $1604\left(\delta_{\mathrm{H}-\mathrm{O}-\mathrm{H})}\right.$ & \\
& $3744\left(v_{\mathrm{O}-\mathrm{H}}\right)$ & & \\
& $3564\left(v_{\mathrm{O}-\mathrm{H}}\right)$ & & \\
& $1590\left(\delta_{\mathrm{H}-\mathrm{O}-\mathrm{H})}\right.$ & & \\
\hline
\end{tabular}

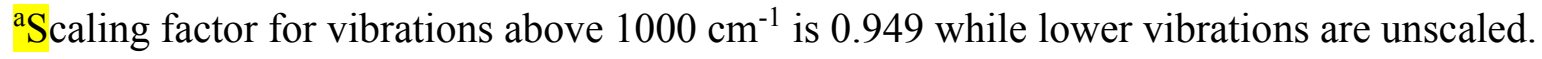




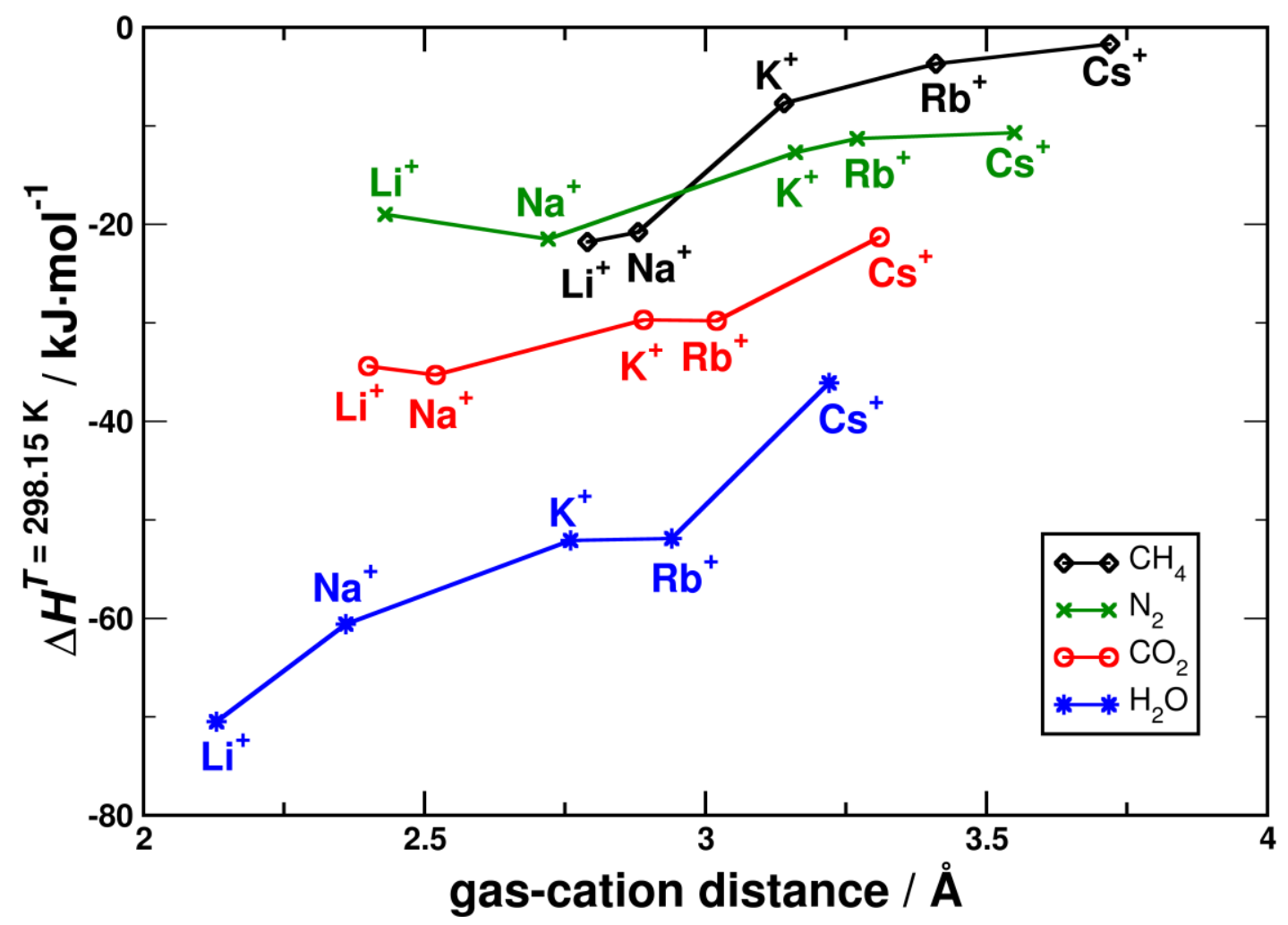

Figure 3. Comparison of the variations in the enthalpies of adsorption of the methane, nitrogen, carbon dioxide and water in alkali metal ion-exchanged ETS-10.

In Figure 3 we summarize the adsorption behavior of the four atmospheric gases considered in the present work onto the alkali metal ion exchanged ETS-10 materials. In general, the adsorption enthalpies decrease with the size of the alkaline metal ion and increase with the magnitude of the quadrupole/dipole moment of the atmospheric gases. The highly polar water molecule interacts more strongly with the ETS-10 materials than any other gas. The remaining molecules are apolar or mildly polar, and the strength of adsorption is dictated by the molecular 
quadrupole moment and the polarizability. The quadrupole moment decreases from carbon dioxide (large quadrupole moment) to nitrogen (moderate quadrupole moment) to methane (zero). In the case of $\mathrm{K}^{+}, \mathrm{Rb}^{+}$and $\mathrm{Cs}^{+}$exchanged ETS-10 materials, the ordering of the strength of adsorption follows the ordering of the molecular quadrupole moments. However, in the case of $\mathrm{Li}^{+}$and $\mathrm{Na}^{+}$ exchanged ETS-10, the adsorption enthalpy of methane is slightly more negative than that of nitrogen. This behavior seems to be governed at smaller adsorbate-cation distances by the molecular polarizability of the adsorbates, which is higher in methane than in molecular nitrogen. ${ }^{53}$ As such, dispersion interactions are expected to be stronger in the former. Overall, adsorption of polar molecules is dominated by electrostatic interactions, while adsorption of less polar molecules relies on a balance between electrostatics and dispersion interactions with the framework atoms.

\section{Conclusions}

The interactions of $\mathrm{CH}_{4}, \mathrm{CO}_{2}, \mathrm{~N}_{2}$, and $\mathrm{H}_{2} \mathrm{O}$ species with ETS-10 having extra framework alkali metal cations in the $12 \mathrm{MR}$ of ETS-10 were studied by means of density functional theory. The strength of gas-framework interactions increases in the order $\mathrm{Cs}^{+}<\mathrm{Rb}^{+}<\mathrm{K}^{+}<\mathrm{Na}^{+}<\mathrm{Li}^{+}$ regardless of adsorbate polarity. The enthalpies of interaction at $T=298.15 \mathrm{~K}$ range between -1.7 $\mathrm{kJ} \cdot \mathrm{mol}^{-1}(\mathrm{Cs}-3 \mathrm{Na}-\mathrm{ETS}-10)$ and $-21.8 \mathrm{~kJ} \cdot \mathrm{mol}^{-1}(\mathrm{Li}-3 \mathrm{Na}-\mathrm{ETS}-10)$ for the least polar molecule, methane, and between $-36.1 \mathrm{~kJ} \cdot \mathrm{mol}^{-1}(\mathrm{Cs}-3 \mathrm{Na}-\mathrm{ETS}-10)$ and $-70.5 \mathrm{~kJ} \cdot \mathrm{mol}^{-1}$ (Li-3Na-ETS-10) for the most polar molecule, water. The vibrational frequencies calculated at the M06-L/6-31++G(d,p) level of theory are in very good agreement with the available experimental vibrations characteristic of the formation of $\mathrm{M}^{+}$... adsorbate adducts for alkali metal cations located at the $\mathrm{M}_{\text {III }}$ position in the 12-membered channels. The calculations suggest that due to the strong gas-material interactions found for the polar $\mathrm{H}_{2} \mathrm{O}$ and the quadrupolar $\mathrm{CO}_{2}$ species, the regeneration of lithium 
exchanged ETS-10 materials after usage in separation and/or catalysis processes could be an energy intensive process as compared to the potassium or cesium exchanged ETS-10.

\section{Acknowledgments}

The authors thank Dr. Moisés L. Pinto, University of Lisbon, for fruitful discussions. This work was developed in the scope of the Projects POCI-01-0145-FEDER-007679 | UID/CTM/50011/2013 (CICECO), PTDC/EQU-EQU/100476/2008 and Programa Investigador FCT, financed by national funds through the FCT/MEC and cofinanced by FEDER under the PT2020 Partnership Agreement. RSP gratefully acknowledges a post-doctoral fellowship from FCT with reference SFRH/BPD/70283/2010 and the Science and Engineering Research Board (SERB), Department of Science and Technology (DST), Govt. of India, for the award of National Post-Doctoral Fellowship (SERB-NPDF) with reference PDF/2017/001252. 


\section{References}

(1) Frequently Asked Questions About Landfill Gas and How It Affects Public Health, Safety, and the Environment; United States Environmental Protection Agency, Office of Air and Radiation.

(2) Yang, R. T.; Kikkinides, E. S.: New Sorbents for Olefin/Paraffin Separations by Adsorption via $\pi$-Complexation. AIChE J. 41, 1995, 509-517.

(3) Oleksiienko, O.; Wolkersdorfer, C.; Sillanpää, M.: Titanosilicates in Cation Adsorption and Cation Exchange - A Review. Chem. Eng. J. 317, 2017, 570-585.

(4) Kuznicki, S. M.: Large-Pored Crystalline Titanium Molecular Sieve Zeolites. US Patent 4853202 A, August 1, 1989.

(5) Anderson, M. W.; Terasaki, O.; Ohsuna, T.; Philippou, A.; MacKay, S. P.; Ferreira, A.; Rocha, J.; Lidin, S.: Structure of the Microporous Titanosilicate ETS-10. Nature 367, 1994, 347-351.

(6) Anderson, M. W.; Terasaki, O.; Ohsuna, T.; Malley, P. J. O.; Philippou, A.; Mackay, S. P.; Ferreira, A.; Rocha, J.; Lidin, S.: Microporous Titanosilicate ETS-10: A Structural Survey. Philos. Mag. Part B 71, 1995, 813-841.

(7) Das, T. K.; Chandwadkar, A. J.; Sivasanker, S.: Studies on the Synthesis, Characterization and Catalytic Properties of the Large Pore Titanosilicate, ETS-10. J. Mol. Catal. A Chem. 107, 1996, 199-205.

(8) Yang, X.; Blosser, P. W.: Location and Bonding of Cations in ETS-10 Titanosilicate Molecular Sieve: A Multinuclear NMR Investigation. Zeolites. September 1996, pp 237243.

(9) Al-Baghli, N. A.; Loughlin, K. F.: Adsorption of Methane, Ethane, and Ethylene on Titanosilicate ETS-10 Zeolite. J. Chem. Eng. Data 50, 2005, 843-848.

(10) Ansón, A.; Kuznicki, S. M.; Kuznicki, T.; Haastrup, T.; Wang, Y.; Lin, C. C. H.; Sawada, J. A.; Eyring, E. M.; Hunter, D.: Adsorption of Argon, Oxygen, and Nitrogen on Silver Exchanged ETS-10 Molecular Sieve. Microporous Mesoporous Mater. 109, 2008, 577580 .

(11) Nalaparaju, A.; Zhao, X. S.; Jiang, J.: Molecular Interplay of Cations and Nonpolar/Polar Sorbates in Titanosilicate ETS-10. J. Phys. Chem. C 112, 2008, 12861-12868.

(12) Anson, A.; Lin, C. C. H.; Kuznicki, S. M.; Sawada, J. A.: Adsorption of Carbon Dioxide, Ethane, and Methane on Titanosilicate Type Molecular Sieves. Chem. Eng. Sci. 64, 2009, 3683-3687.

(13) Park, S. W.; Yun, Y. H.; Kim, S. D.; Yang, S. T.; Ahn, W. S.; Seo, G.; Kim, W. J.: CO2 Retention Ability on Alkali Cation Exchanged Titanium Silicate, ETS-10. J. Porous Mater. 17, 2009, 589-595.

(14) Shi, M.; Kim, J.; Sawada, J. A.; Lam, J.; Sarabadan, S.; Kuznicki, T. M.; Kuznicki, S. M.: Production of Argon Free Oxygen by Adsorptive Air Separation on Ag-ETS-10. AIChE J. 59, 2013, 982-987.

(15) Anson, A.; Lin, C. C. H.; Kuznicki, T. M.; Kuznicki, S. M.: Separation of Ethylene/Ethane 
Mixtures by Adsorption on Small-Pored Titanosilicate Molecular Sieves. Chem. Eng. Sci. 65, 2010, 807-811.

(16) Anson, A.; Wang, Y.; Lin, C. C. H.; Kuznicki, T. M.; Kuznicki, S. M.: Adsorption of Ethane and Ethylene on Modified ETS-10. Chem. Eng. Sci. 63, 2008, 4171-4175.

(17) Kuznicki, S. M.; Anson, A.; Koenig, A.; Kuznicki, T. M.; Haastrup, T.; Eyring, E. M.; Hunter, D.: Xenon Adsorption on Modified ETS-10. J. Phys. Chem. C 111, 2007, 15601562.

(18) Pahinkar, D. G.; Garimella, S.; Robbins, T. R.: Feasibility of Temperature Swing Adsorption in Adsorbent-Coated Microchannels for Natural Gas Purification. Ind. Eng. Chem. Res. 56, 2017, 5403-5416.

(19) de Man, A. J. M.; Sauer, J.: Coordination, Structure, and Vibrational Spectra of Titanium in Silicates and Zeolites in Comparison with Related Molecules. An Ab Initio Study. J. Phys. Chem. 100, 1996, 5025-5034.

(20) Ching, W.; Xu, Y.-N.; Gu, Z.: Structure and Properties of Microporous Titanosilicate Determined by First-Principles Calculations. Phys. Rev. B 54, 1996, R15585-R15589.

(21) Bordiga, S.; Turnes Palomino, G.; Zecchina, A.; Ranghino, G.; Giamello, E.; Lamberti, C.: Stoichiometric and Sodium-Doped Titanium Silicate Molecular Sieve Containing Atomically Defined -OTiOTiO- Chains: Quantum Ab Initio Calculations, Spectroscopic Properties, and Reactivity. J. Chem. Phys. 112, 2000, 3859.

(22) Zimmerman, A. M.; Doren, D. J.; Lobo, R. F.: Electronic and Geometric Properties of ETS10: QM/MM Studies of Cluster Models. J. Phys. Chem. B 110, 2006, 8959-8964.

(23) Koç, M.; Galioglu, S.; Toffoli, D.; Ustunel, H.; Akata, B.: Understanding the Effects of IonExchange in Titanosilicate ETS-10: A Joint Theoretical and Experimental Study. J. Phys. Chem. C 118, 2014, 27281-27291.

(24) Guo, M.; Feng, Z.; Li, G.; Hofmann, J. P.; Pidko, E. A.; Magusin, P. C. M. M.; Guo, Q.; Weckhuysen, B. M.; Hensen, E. J. M.; Fan, F.; Li, C.: "Extracting" the Key Fragment in ETS-10 Crystallization and Its Application in AM-6 Assembly. Chemistry 18, 2012, 12078 12084.

(25) Pillai, R. S.; Jorge, M.; Gomes, J. R. B.: Interaction of Atmospheric Gases with ETS-10: A DFT Study. Microporous Mesoporous Mater. 190, 2014, 38-45.

(26) Waghmode, S. B.; Vetrivel, R.; Gopinath, C. S.; Sivasanker, S.: Influence of Cation Exchange on M-Pt-ETS-10 Molecular Sieve: Correlation between Ab Initio Results, Catalytic Activity, and Physicochemical Investigations. J. Phys. Chem. B 108, 2004, 11541-11548.

(27) Shough, A. M.; Doren, D. J.; Ogunnaike, B.: Transition Metal Substitution in ETS-10: DFT Calculations and a Simple Model for Electronic Structure Prediction. Chem. Mater. 21, 2009, 1232-1241.

(28) Zhao, Y.; Truhlar, D. G.: A New Local Density Functional for Main-Group Thermochemistry, Transition Metal Bonding, Thermochemical Kinetics, and Noncovalent Interactions. J. Chem. Phys. 125, 2006, 194101.

(29) Frisch, M. J.; Trucks, G. W.; Schlegel, H. B.; Scuseria, G. E.; Robb, M. A.; Cheeseman, J. 
R.; Scalmani, G.; Barone, V.; Mennucci, B.; Petersson, G. A.; Nakatsuji, H.; Caricato, M.; Li, X.; Hratchian, H. P.; Izmaylov, A. F.; Bloino, J.; Zheng, G.; Sonnenberg, J. L.; Hada, M. et al.: Gaussian 09, Rev. B.01. Gaussian, Inc., Wallingford CT 2009.

(30) Shi, M.: Applications of Titanosilicate Molecular Sieves in Gas Separation, PhD Thesis, Department of Chemical and Materials Engineering, University of Alberta Edmonton.

(31) Valero, R.; Gomes, J. R. B.; Truhlar, D. G.; Illas, F.: Good Performance of the M06 Family of Hybrid Meta Generalized Gradient Approximation Density Functionals on a Difficult Case: CO Adsorption on MgO(001). J. Chem. Phys. 129, 2008, 124710.

(32) Valero, R.; Gomes, J. R. B.; Truhlar, D. G.; Illas, F.: Density Functional Study of CO and NO Adsorption on Ni-Doped MgO(100). J. Chem. Phys. 132, 2010, 104701.

(33) Toda, J.; Fischer, M.; Jorge, M.; Gomes, J. R. B.: Water Adsorption on a Copper Formate Paddlewheel Model of CuBTC: A Comparative MP2 and DFT Study. Chem. Phys. Lett. 587, 2013, 7-13.

(34) Ramalho, J. P. P.; Gomes, J. R. B.; Illas, F.: Accounting for van Der Waals Interactions between Adsorbates and Surfaces in Density Functional Theory Based Calculations: Selected Examples. RSC Adv. 3, 2013, 13085-13100.

(35) Gomes, J. R. B.; Cordeiro, M. N. D. S.; Jorge, M.: Gas-Phase Molecular Structure and Energetics of Anionic Silicates. Geochim. Cosmochim. Acta 72, 2008, 4421-4439.

(36) Grillo, M. E.; Carrazza, J.: Computational Modeling of the Nonframework Cation Location and Distribution in Microporous Titanosilicate ETS-10. J. Phys. Chem. 100, 1996, 1226112264.

(37) Wang, X.; Jacobson, A. J.: Crystal Structure of the Microporous Titanosilicate ETS-10 Refined from Single Crystal X-Ray Diffraction Data. Chem. Commun. No. 11, 1999, 973974.

(38) Pillai, R. S.; Gomes, J. R. B.; Jorge, M.: Molecular Simulation of the Adsorption of Methane in Engelhard Titanosilicate Frameworks. Langmuir 30, 2014, 7435-7446.

(39) Zecchina, A.; Otero Areán, C.; Turnes Palomino, G.; Geobaldo, F.; Lamberti, C.; Spoto, G.; Bordiga, S.: The Vibrational Spectroscopy of H2, N2, CO and NO Adsorbed on the Titanosilicate Molecular Sieve ETS-10. Phys. Chem. Chem. Phys. 1, 1999, 1649-1657.

(40) Pavel, C. C.; Zibrowius, B.; Löffler, E.; Schmidt, W.: On the Influence of Ion Exchange on the Local Structure of the Titanosilicate ETS-10. Phys. Chem. Chem. Phys. 9, 2007, 34403446.

(41) Boys, S.; Bernardi, F.: The Calculation of Small Molecular Interactions by the Differences of Separate Total Energies. Some Procedures with Reduced Errors. Mol. Phys. No. May 2012, 1970, 553-566.

(42) Pillai, R. S.; Jorge, M.; Gomes, J. R. B.: A Density Functional Theory Study on the Interaction of Paraffins, Olefins, and Acetylenes with Na-ETS-10. Theor. Chem. Acc. 134, 2015, 42.

(43) Merrick, J. P.; Moran, D.; Radom, L.: An Evaluation of Harmonic Vibrational Frequency Scale Factors. J. Phys. Chem. A 111, 2007, 11683-11700.

Mihailova, B.; Valtchev, V.; Mintova, S.; Konstantinov, L.: Vibrational Spectra of ETS-4 
and ETS-10. Zeolites 16, 1996, 22-24.

(45) Das, T. K.; Chandwadkar, A. J.; Budhkar, A. P.; Sivasanker, S.: Studies on the Synthesis of ETS-10 II. Use of Organic Templates. Microporous Mater. 5, 1996, 401-410.

(46) Yang, X.; Paillaud, J.-L.; van Breukelen, H. F. W. .; Kessler, H.; Duprey, E.: Synthesis of Microporous Titanosilicate ETS-10 with TiF4 or TiO2. Microporous Mesoporous Mater. 46, 2001, 1-11.

(47) Waghmode, S. B.; Vetrivel, R.; Hegde, S. G.; Gopinath, C. S.; Sivasanker, S.: Physicochemical Investigations of the Basicity of the Cation Exchanged ETS-10 Molecular Sieves. J. Phys. Chem. B 107, 2003, 8517-8523.

(48) Allouche, A.-R.: Gabedit-A Graphical User Interface for Computational Chemistry Softwares. J. Comput. Chem. 32, 2011, 174-182.

(49) Kishima, M.; Okubo, T.: Characterization of Microporous Titanosilicate ETS-10 by Infrared Spectroscopy with Methane as a Probe Molecule for Basic Sites. J. Phys. Chem. B 107, 2003, 8462-8468.

(50) Gallo, M.; Nenoff, T. M.; Mitchell, M. C.: Selectivities for Binary Mixtures of Hydrogen/Methane and Hydrogen/Carbon Dioxide in Silicalite and ETS-10 by Grand Canonical Monte Carlo Techniques. Fluid Phase Equilib. 247, 2006, 135-142.

(51) Xamena, F. X. L. i; Zecchina, A.: FTIR Spectroscopy of Carbon Dioxide Adsorbed on Sodium- and Magnesium-Exchanged ETS-10 Molecular Sieves. Phys. Chem. Chem. Phys. 4, 2002, 1978-1982.

(52) Krisnandi, Y. K.; Howe, R. F.: Effects of Ion-Exchange on the Photoreactivity of ETS- 10. Appl. Catal. A Gen. 307, 2006, 62-69.

(53) NIST Computational Chemistry Comparison and Benchmark Database, Rel. 17b.; Johnson III, R. D., Ed.; The National Institute of Standards and Technology: Gaithersburg. 


\section{A DFT study on the interaction of small molecules with alkali metal ion-exchanged ETS-10}

Renjith S. Pillai, ${ }^{1, \#}$ Miguel Jorge, ${ }^{2}$ José R. B. Gomes ${ }^{1, *}$

${ }^{1}$ CICECO, Departamento de Química, Universidade de Aveiro, Campus Universitário de Santiago, P-3810-193 Aveiro, Portugal

${ }^{2}$ Department of Chemical and Process Engineering, University of Strathclyde, 75 Montrose

Street, Glasgow G1 1XJ, United Kingdom

*Corresponding author. E-mail: jrgomes@ua.pt

Phone: +351234401423

Fax: +351234401470

\#Present address: Chemical Sciences and Technology Division, CSIR-National Institute for Interdisciplinary Science and Technology (CSIRNIIST), Thiruvananthapuram-695019, India 
Table S1. Comparison of calculated and experimental vibrations $\left(\mathrm{cm}^{-1}\right)$ for Na-ETS-10 and alkali metal ion-exchanged Na-ETS-10.

\begin{tabular}{|c|c|c|c|c|c|}
\hline \multirow[b]{2}{*}{ Adsorbent } & \multirow[b]{2}{*}{ Calculated $^{\mathrm{a}}$} & \multicolumn{4}{|c|}{ Experimental } \\
\hline & & $\begin{array}{c}\text { Yang } \\
\text { et al. [1] }\end{array}$ & $\begin{array}{c}\text { Waghmode } \\
\text { et al. [2] }\end{array}$ & $\begin{array}{c}\text { Mihailova } \\
\text { et al. [3] }\end{array}$ & $\begin{array}{c}\text { Das } \\
\text { et al. [4] }\end{array}$ \\
\hline Li-3Na-ETS10 & $\begin{array}{c}1203,1179,1163, \\
1150,1127,1122, \\
1110,1083,1000, \\
784,745,743,720, \\
708,565,472,458, \\
404\end{array}$ & \multirow{5}{*}{$\begin{array}{c}1140,1123, \\
1090,1032, \\
882,750, \\
731,665, \\
610,555, \\
515,490, \\
456,440,434\end{array}$} & \multirow{5}{*}{$\begin{array}{c}1190,1058- \\
1070,985, \\
785,745, \\
708,508,447\end{array}$} & \multirow{5}{*}{$\begin{array}{c}1068,780, \\
690,575, \\
450,376,245\end{array}$} & \multirow{5}{*}{$\begin{array}{c}1100,1000, \\
960,730, \\
640,550,440\end{array}$} \\
\hline Na-3Na-ETS10 & $\begin{array}{c}1192,1176,1167, \\
1163,1153,1120, \\
1117,1102,1084, \\
1078,1004,785, \\
747,725,711,533, \\
474,465,397\end{array}$ & & & & \\
\hline $\mathrm{K}-3 \mathrm{Na}-\mathrm{ETS} 10$ & $\begin{array}{c}1175,1156,1142, \\
1111,1108,1092, \\
1076,1005,961, \\
811,779,741,740, \\
706,472,463,393\end{array}$ & & & & \\
\hline Rb-3Na-ETS10 & $\begin{array}{c}\text { 1154, 1152, 1141, } \\
1108,1104,1091, \\
1073,1066,1005, \\
960,808,776,771, \\
740,739,707,471, \\
458,391,361\end{array}$ & & & & \\
\hline Cs-3Na-ETS10 & $\begin{array}{c}1167,1154,1150, \\
1139,1106,1101, \\
1089,1072,1064, \\
1007,959,807, \\
774,769,738,703, \\
532,470,457,390, \\
360\end{array}$ & & & & \\
\hline
\end{tabular}

${ }^{a}$ Most prominent (intensity > 300) peaks in the spectra calculated with the M06-L approach. All calculated vibrations are unscaled. 
Table S2. Cation (M) to methane and cation to framework oxygens distances $(\AA)$ optimized with the M06-L approach and applying BSSE corrections.

\begin{tabular}{|l|c|c|c|c|c|c|}
\hline \multirow{2}{*}{ Adsorbent } & \multicolumn{7}{|c|}{ Parameter } \\
\cline { 2 - 7 } & ${\mathrm{M}-\mathrm{CH}_{4}{ }^{\mathrm{a}}}^{*}$ & $\mathrm{M}-\mathrm{O} 1$ & $\mathrm{M}-\mathrm{O} 2$ & $\mathrm{M}-\mathrm{O} 5$ & $\mathrm{M}-\mathrm{O} 6$ & M-O7 \\
\hline Li-3Na-ETS10 & 2.79 & 2.11 & 2.32 & 1.89 & 2.15 & 2.36 \\
\hline $\mathrm{Na}-3 \mathrm{Na}-E T S 10$ & 2.88 & 2.42 & 2.42 & 2.25 & 2.42 & 2.42 \\
\hline K-3Na-ETS10 & 3.14 & 2.74 & 2.74 & 2.68 & 2.71 & 2.72 \\
\hline $\mathrm{Rb}-3 \mathrm{Na}-E T S 10$ & 3.41 & 2.91 & 2.91 & 2.97 & 2.92 & 2.92 \\
\hline Cs-3Na-ETS10 & 3.72 & 3.17 & 3.17 & 3.31 & 3.15 & 3.15 \\
\hline
\end{tabular}

${ }^{\mathrm{a}}$ Distance to the carbon atom of $\mathrm{CH}_{4}$.

Table S3. Cation (M) to nitrogen and cation to framework oxygens distances $(\AA)$ optimized with the M06-L approach and applying BSSE corrections.

\begin{tabular}{|l|c|c|c|c|c|c|}
\hline \multirow{2}{*}{ Adsorbent } & \multicolumn{7}{|c|}{ Parameter } \\
\cline { 2 - 7 } & ${\mathrm{M}-\mathrm{N}_{2}{ }^{\mathrm{a}}}$ & $\mathrm{M}-\mathrm{O} 1$ & $\mathrm{M}-\mathrm{O} 2$ & $\mathrm{M}-\mathrm{O} 5$ & $\mathrm{M}-\mathrm{O} 6$ & M-O7 \\
\hline $\mathrm{Li}-3 \mathrm{Na}-E T S 10$ & 2.43 & 2.15 & 2.36 & 1.90 & 2.14 & 2.33 \\
\hline $\mathrm{Na}$-3Na-ETS10 & 2.72 & 2.41 & 2.43 & 2.24 & 2.42 & 2.46 \\
\hline K-3Na-ETS10 & 3.16 & 2.74 & 2.76 & 2.71 & 2.74 & 2.75 \\
\hline $\mathrm{Rb}-3 \mathrm{Na}-E T S 10$ & 3.27 & 2.93 & 2.95 & 2.99 & 2.93 & 2.95 \\
\hline Cs-3Na-ETS10 & 3.55 & 3.14 & 3.19 & 3.33 & 3.14 & 3.17 \\
\hline
\end{tabular}

${ }^{\text {a }}$ Distance to nearest nitrogen atom of $\mathrm{N}_{2}$.

Table S4. Cation (M) to carbon dioxide and cation to framework oxygens distances $(\AA)$ optimized with the M06-L approach and applying BSSE corrections.

\begin{tabular}{|l|c|c|c|c|c|c|}
\hline \multirow{2}{*}{ Adsorbent } & \multicolumn{7}{|c|}{ Parameter } \\
\cline { 2 - 7 } & ${\mathrm{M}-\mathrm{CO}_{2}{ }^{\mathrm{a}}}^{*}$ & M-O1 & M-O2 & M-O5 & M-O6 & M-O7 \\
\hline Li-3Na-ETS10 & 2.40 & 2.18 & 2.34 & 1.91 & 2.13 & 2.35 \\
\hline Na-3Na-ETS10 & 2.52 & 2.42 & 2.46 & 2.25 & 2.42 & 2.44 \\
\hline K-3Na-ETS10 & 2.89 & 2.74 & 2.75 & 2.72 & 2.74 & 2.75 \\
\hline Rb-3Na-ETS10 & 3.02 & 2.92 & 2.94 & 3.01 & 2.93 & 2.94 \\
\hline Cs-3Na-ETS10 & 3.31 & 3.16 & 3.17 & 3.33 & 3.16 & 3.18 \\
\hline
\end{tabular}

${ }^{\mathrm{a} D i s t a n c e}$ to nearest oxygen atom of $\mathrm{CO}_{2}$. 
Table S5. Cation (M) to water and cation to framework oxygens distances $(\AA)$ optimized with the M06-L approach and applying BSSE corrections.

\begin{tabular}{|l|c|c|c|c|c|c|}
\hline \multirow{2}{*}{ Adsorbent } & \multicolumn{7}{|c|}{ Parameter } \\
\cline { 2 - 7 } & ${\mathrm{M}-\mathrm{H}_{2} \mathrm{O}^{\mathrm{a}}}^{*} \mathrm{M}-\mathrm{O} 1$ & $\mathrm{M}-\mathrm{O} 2$ & $\mathrm{M}-\mathrm{O} 5$ & $\mathrm{M}-\mathrm{O} 6$ & $\mathrm{M}-\mathrm{O} 7$ \\
\hline $\mathrm{Li}-3 \mathrm{Na}-E T S 10$ & 2.13 & 1.99 & 2.66 & 1.92 & 2.05 & 2.78 \\
\hline $\mathrm{Na}-3 \mathrm{Na}-E T S 10$ & 2.36 & 2.41 & 2.49 & 2.29 & 2.44 & 2.50 \\
\hline $\mathrm{K}-3 \mathrm{Na}-E T S 10$ & 2.76 & 2.74 & 2.79 & 2.74 & 2.75 & 2.79 \\
\hline $\mathrm{Rb}-3 \mathrm{Na}-E T S 10$ & 2.94 & 2.95 & 3.02 & 3.05 & 2.94 & 2.99 \\
\hline Cs-3Na-ETS10 & 3.22 & 3.16 & 3.21 & 3.34 & 3.15 & 3.21 \\
\hline
\end{tabular}

${ }^{\mathrm{a}}$ Distance to oxygen atom of $\mathrm{H}_{2} \mathrm{O}$. 
(a)
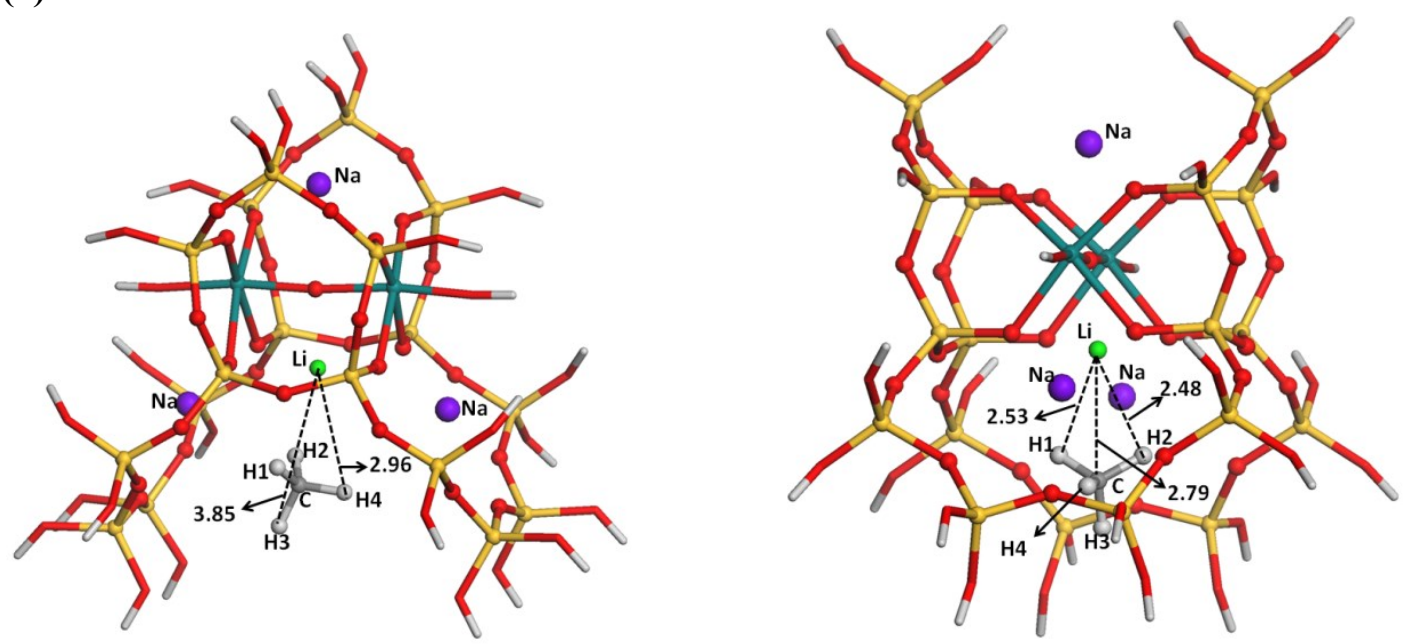

(b)
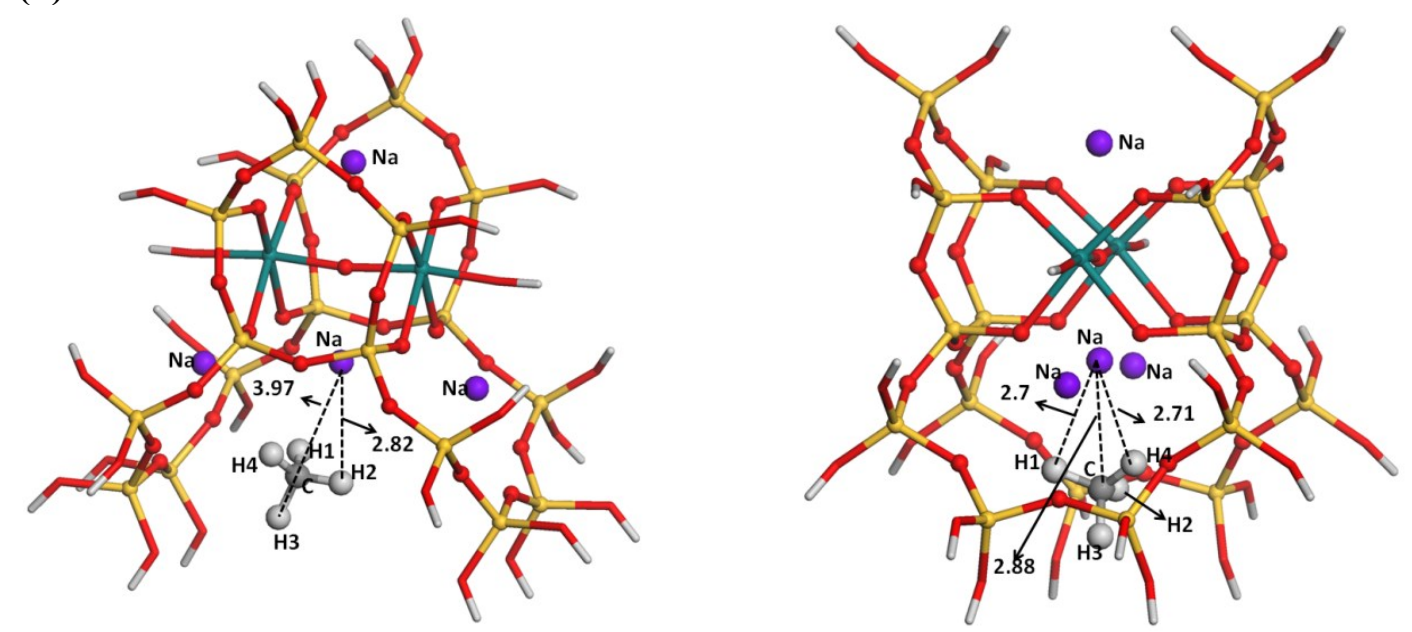

(c)
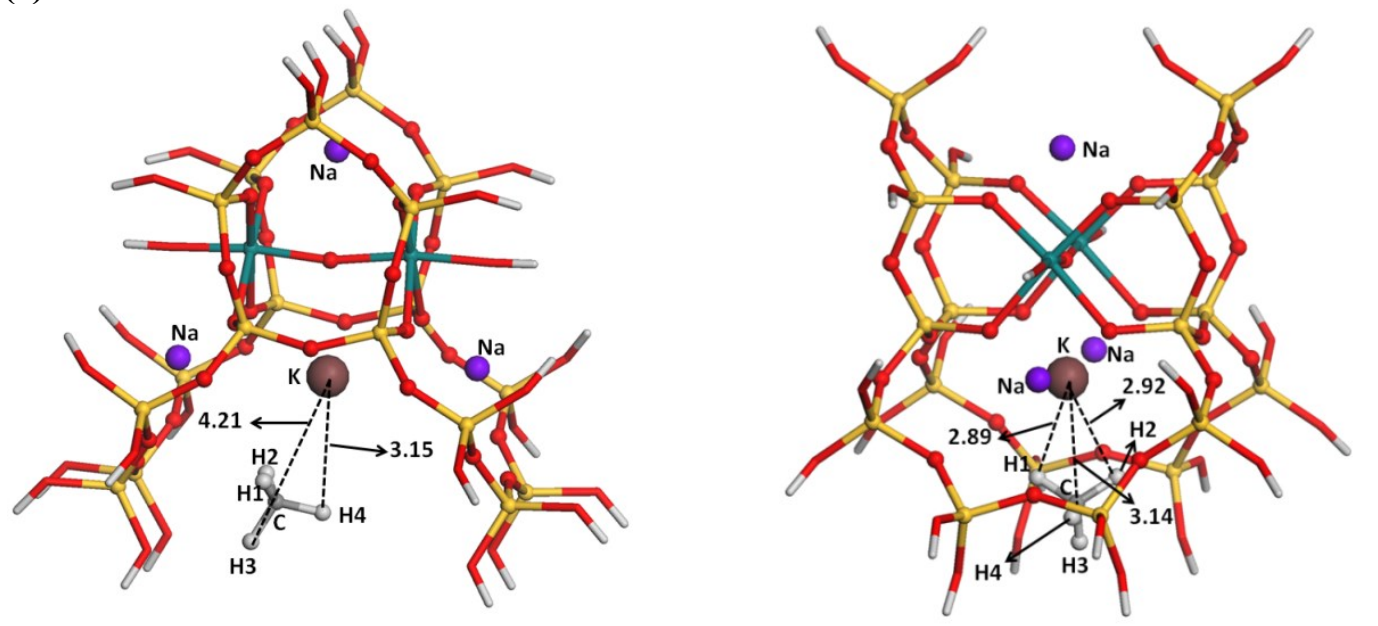
(d)
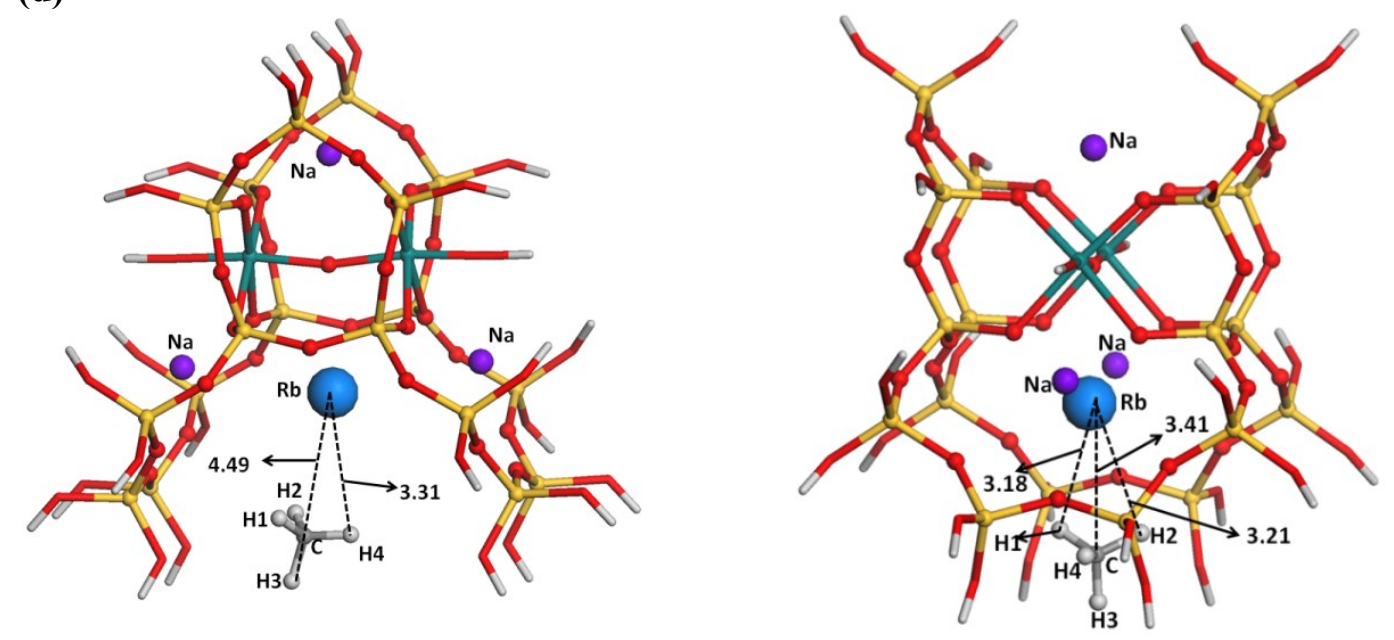

(e)
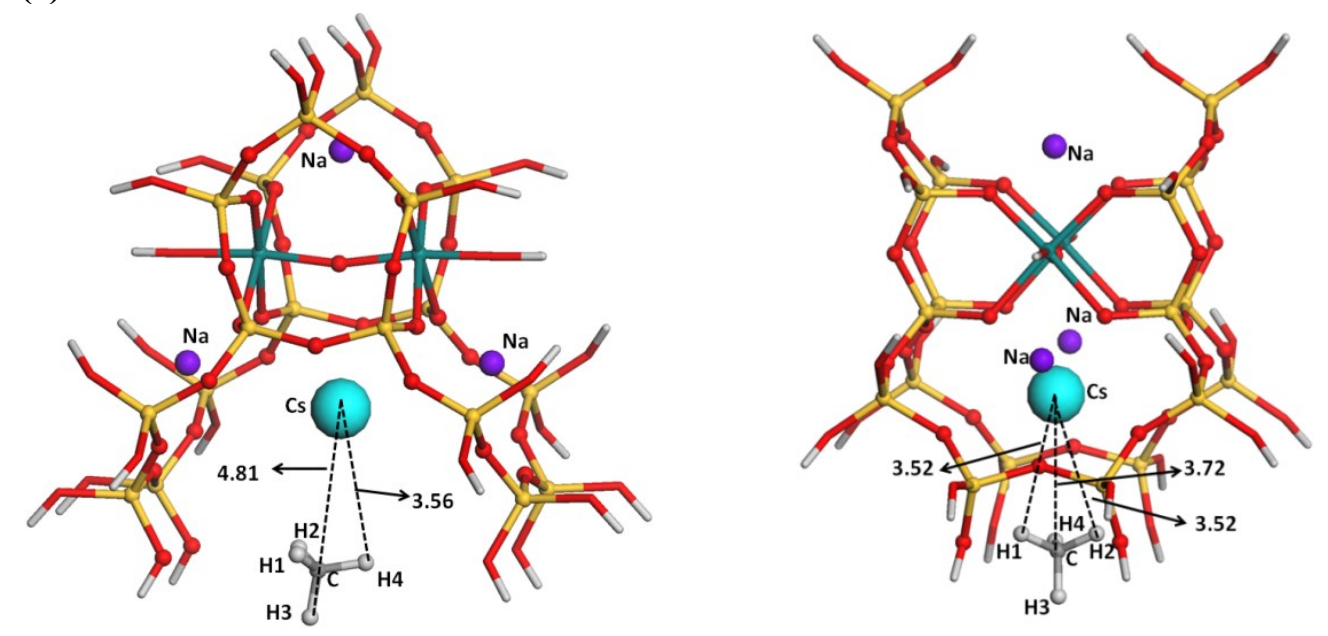

Figure S1. Configurations optimized with the with the M06-L approach and the counterpoise method for $\mathrm{CH}_{4}$ interacting with Li-3Na-ETS-10 (a), Na-3Na-ETS-10 (b), K-3Na-ETS-10 (c), Rb-3Na-ETS-10 (d), and Cs-3Na-ETS-10 (e), viewed along directions parallel (left) and normal (right) to the $-\mathrm{Ti}-\mathrm{O}-\mathrm{Ti}-$ chain. Dashed lines show the distances between the $\mathrm{M}_{\text {III }}$ ion and each individual atom of the sorbate. Color code is: Bluish-green for Ti, yellow for Si, red for $\mathrm{O}$, white for $\mathrm{H}$, green for $\mathrm{Li}$, purple for $\mathrm{Na}$, brown for $\mathrm{K}$, navy blue for $\mathrm{Rb}$ and cyan for $\mathrm{Cs}$. 
(a)
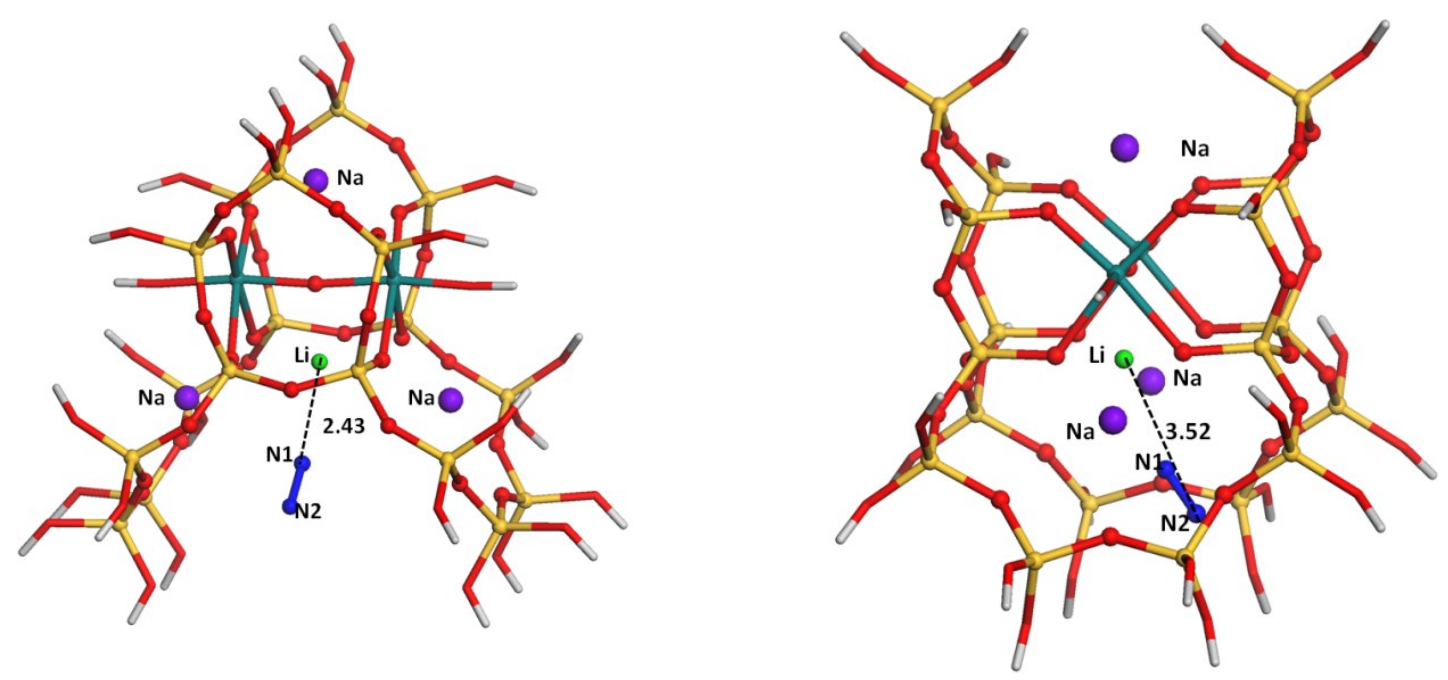

(b)
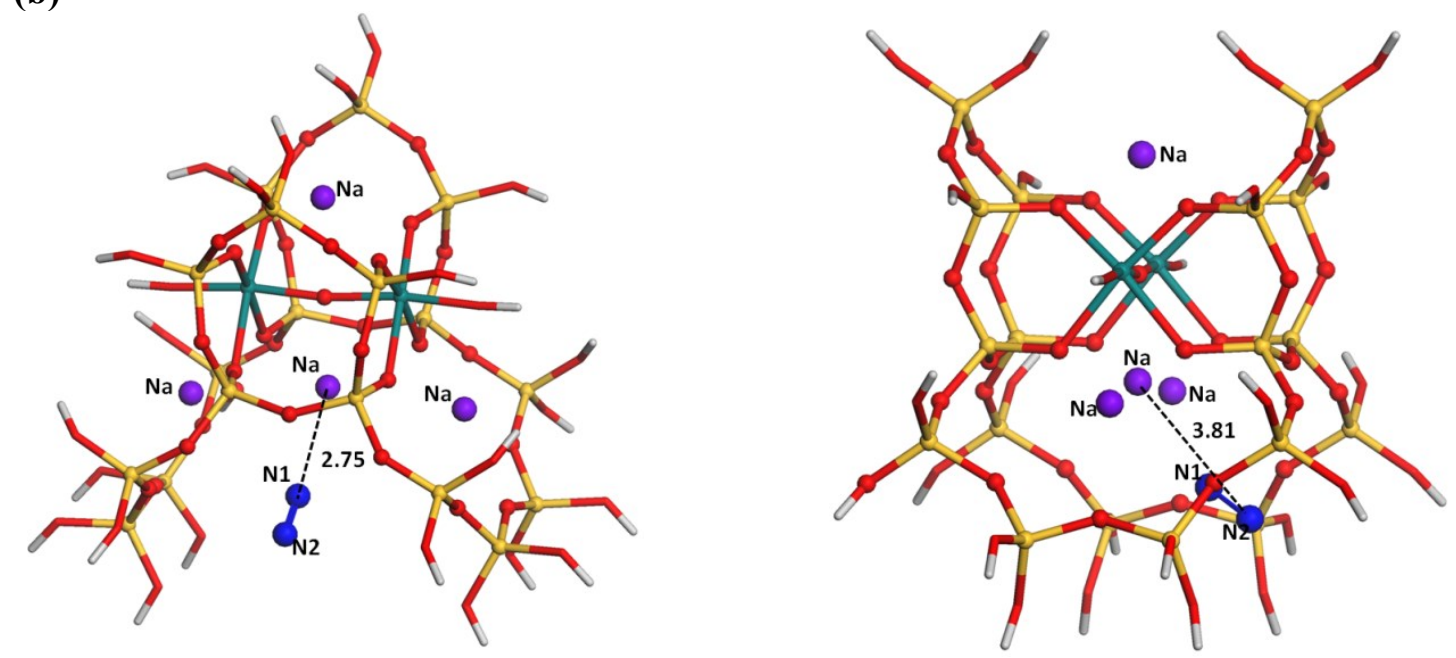

(c)
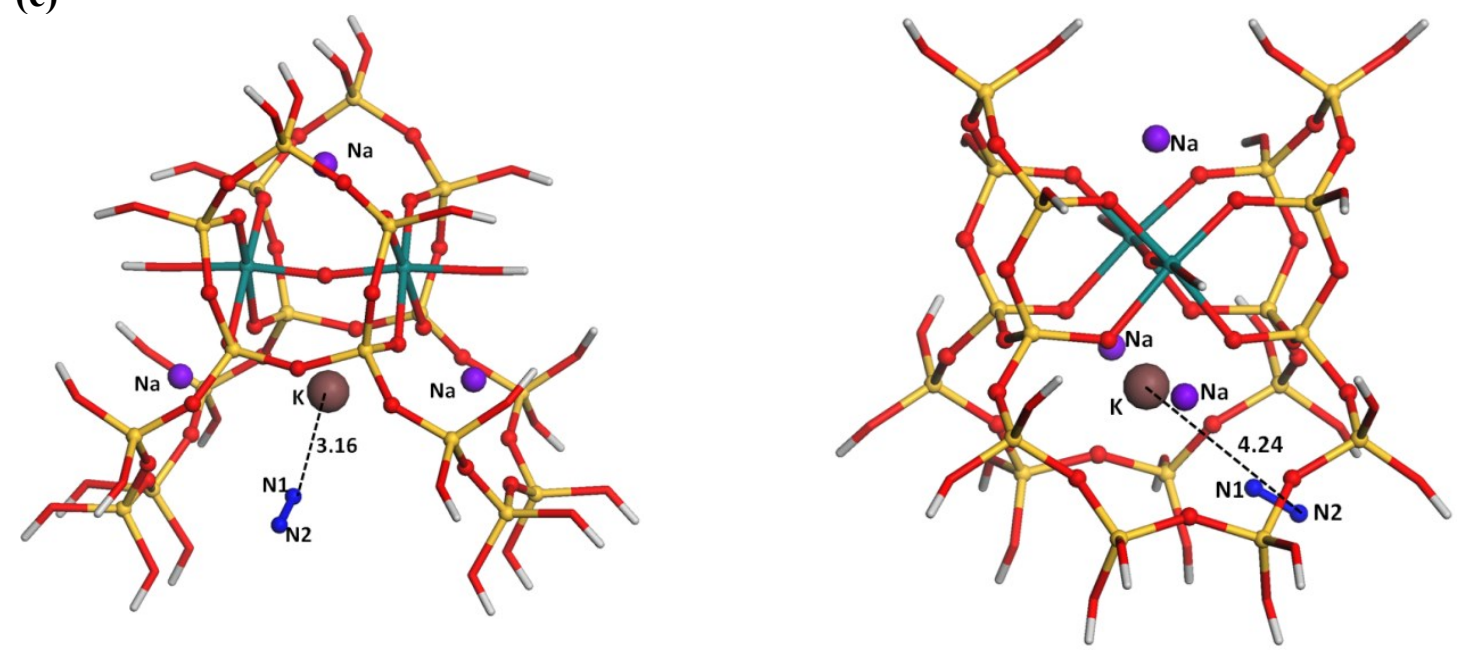
(d)
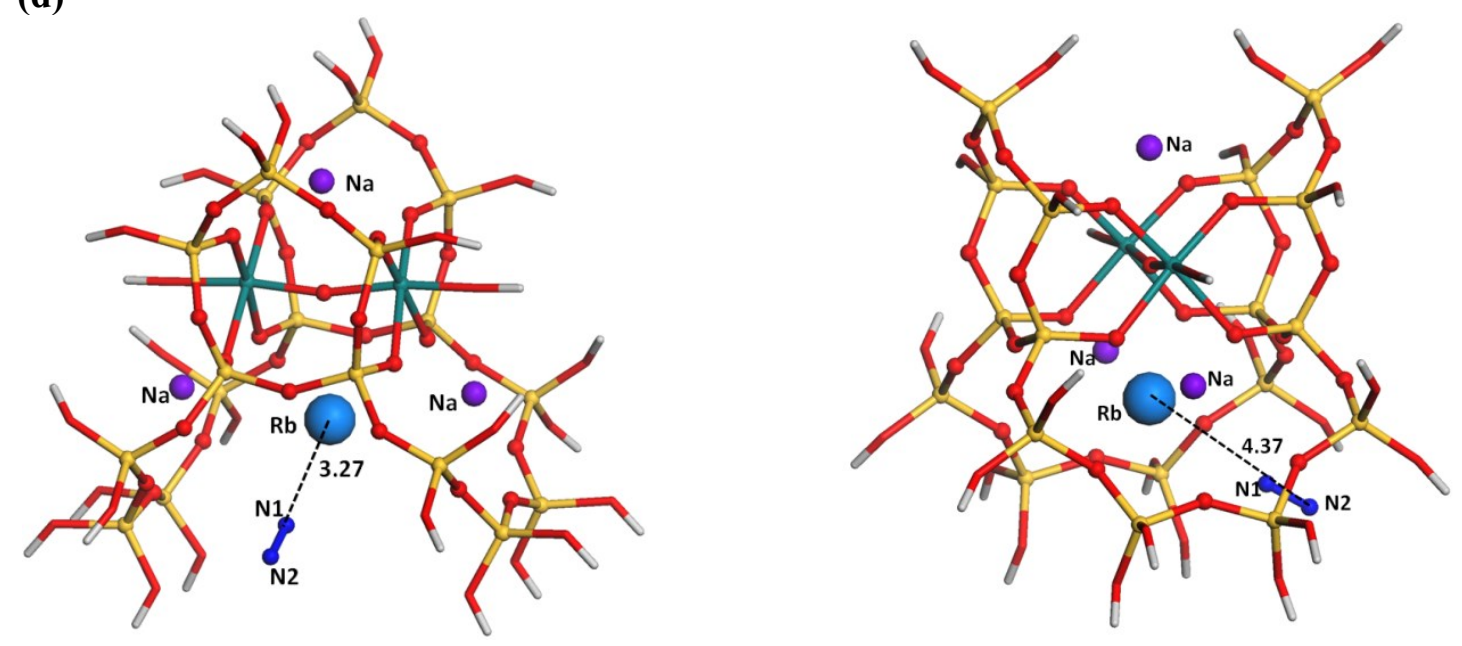

(e)
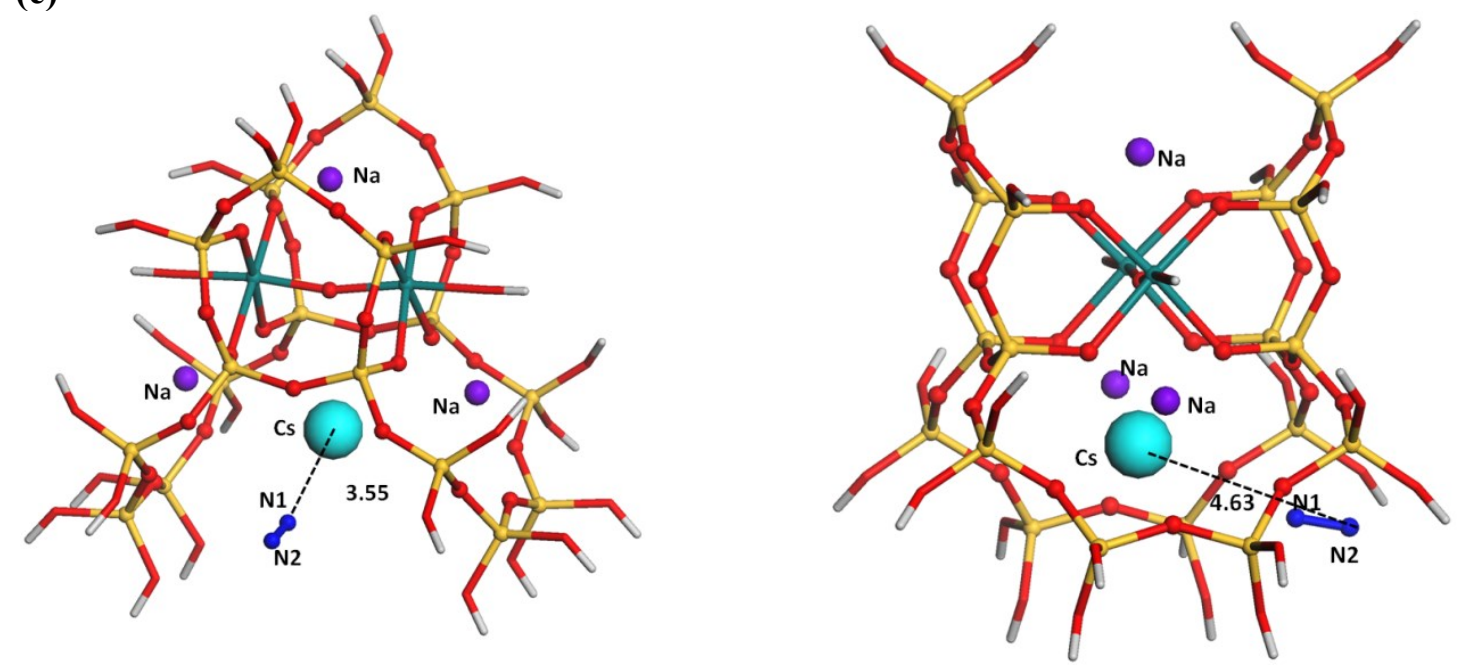

Figure S2. Configurations optimized with the M06-L approach and the counterpoise method for $\mathrm{N}_{2}$ interacting with Li-3Na-ETS-10 (a), Na-3Na-ETS-10 (b), K-3Na-ETS-10 (c), Rb-3NaETS-10 (d), and Cs-3Na-ETS-10 (e), viewed along directions parallel (left) and normal (right) to the -Ti-O-Ti- chain. Dashed lines show the distances between the $\mathrm{M}_{\text {III }}$ ion and each individual atom of the sorbate. Color code is the same as in Figure S1. 
(a)
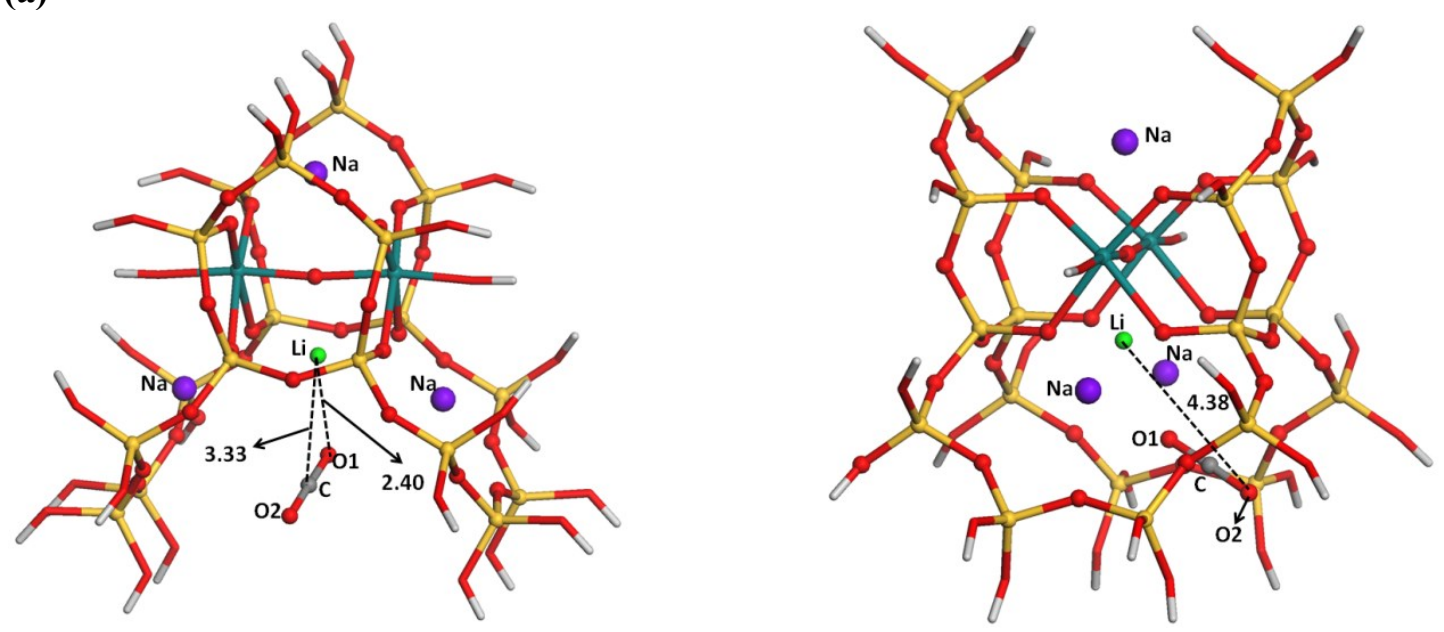

(b)
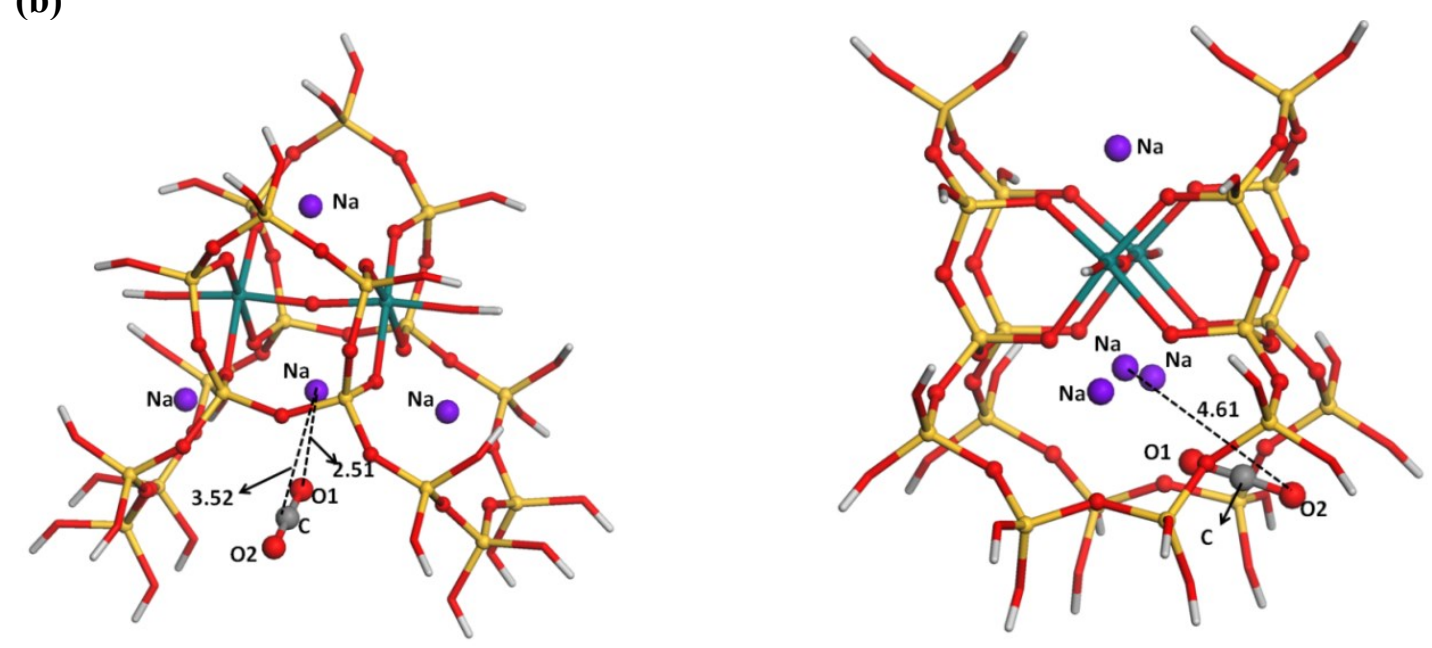

(c)
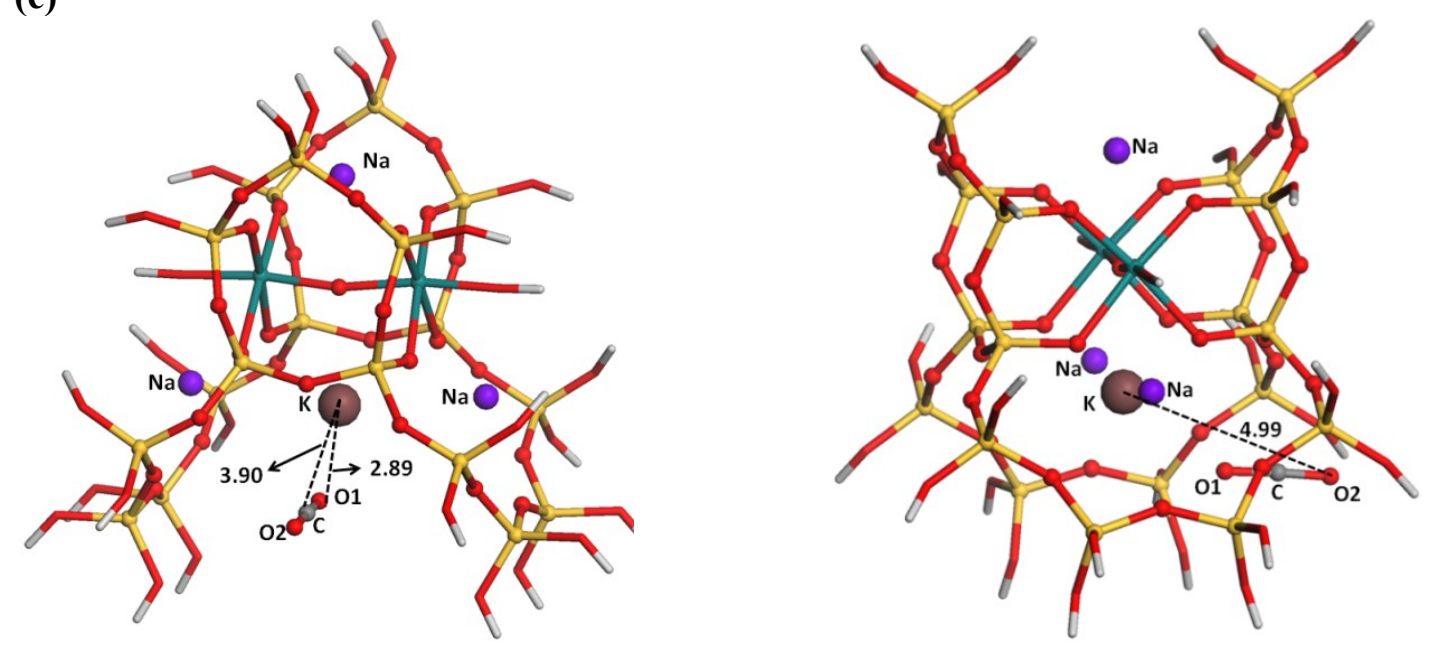
(d)
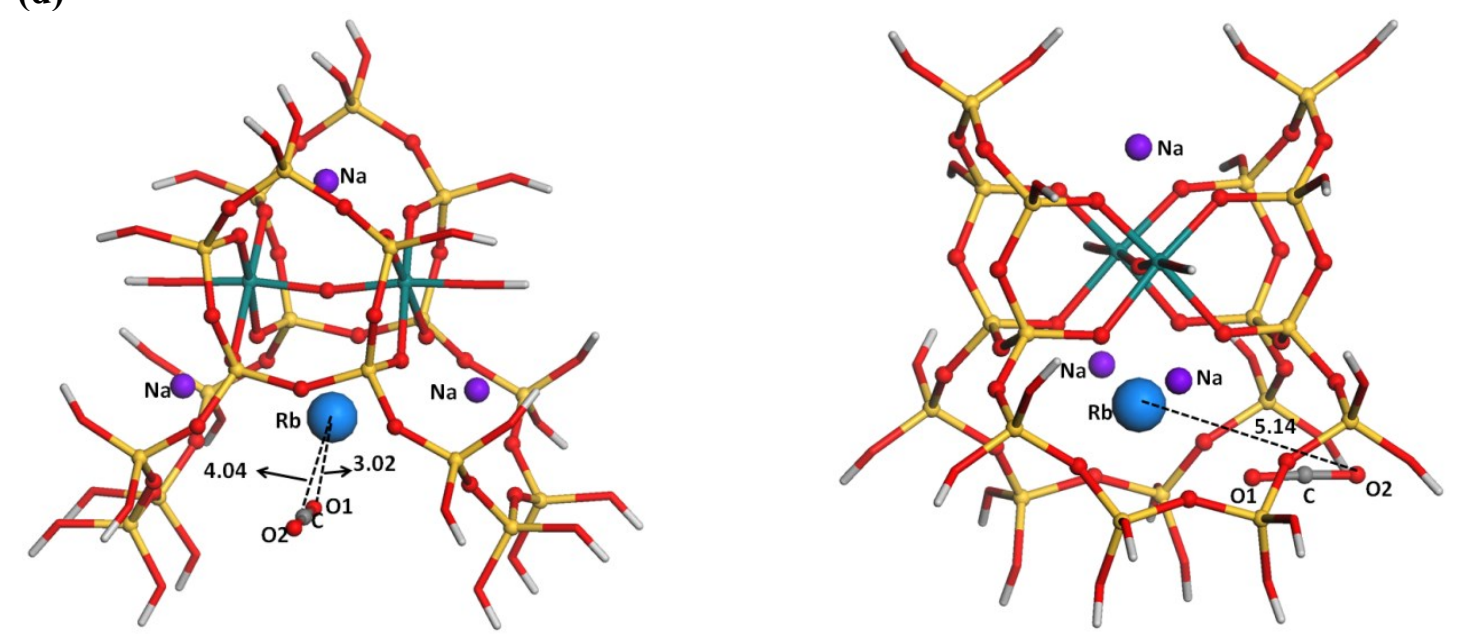

(e)
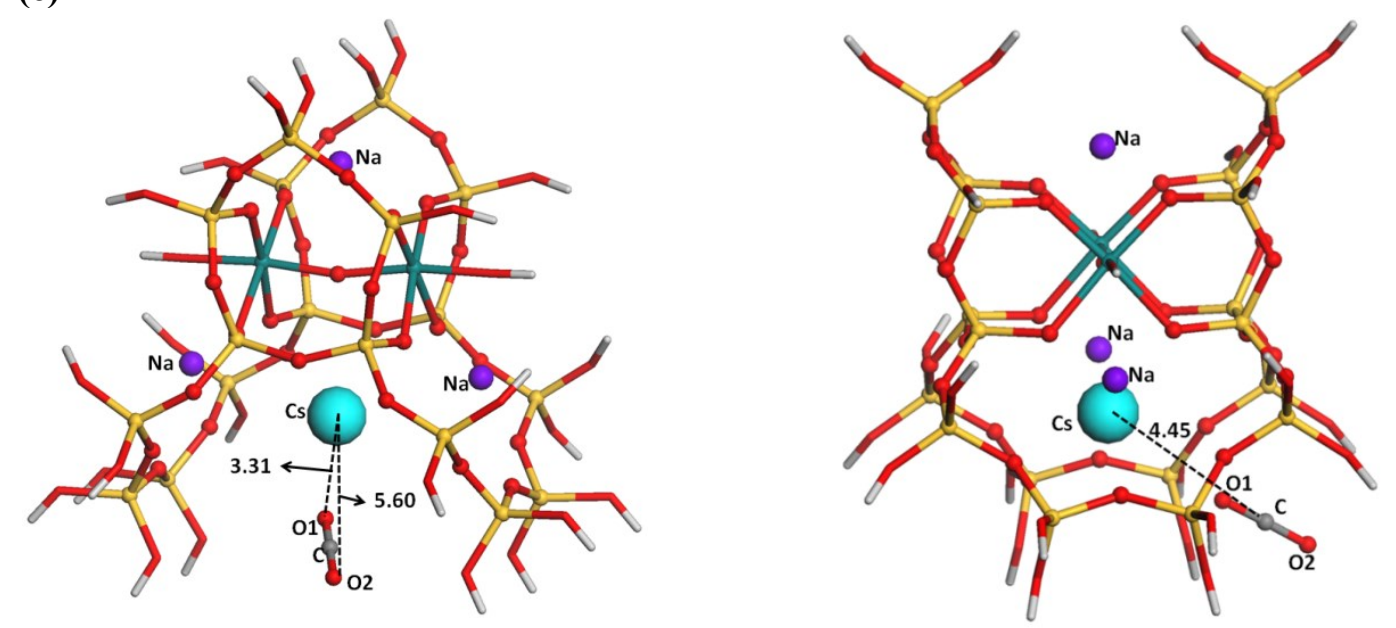

Figure S3. Configurations optimized with the M06-L approach and the counterpoise method for $\mathrm{CO}_{2}$ interacting with Li-3Na-ETS-10 (a), Na-3Na-ETS-10 (b), K-3Na-ETS-10 (c), Rb3Na-ETS-10 (d), and Cs-3Na-ETS-10 (e), viewed along directions parallel (left) and normal (right) to the -Ti-O-Ti- chain. Dashed lines show the distances between the $\mathrm{M}_{\text {III }}$ ion and each individual atom of the sorbate. Color code is the same as in Figure S1. 
(a)
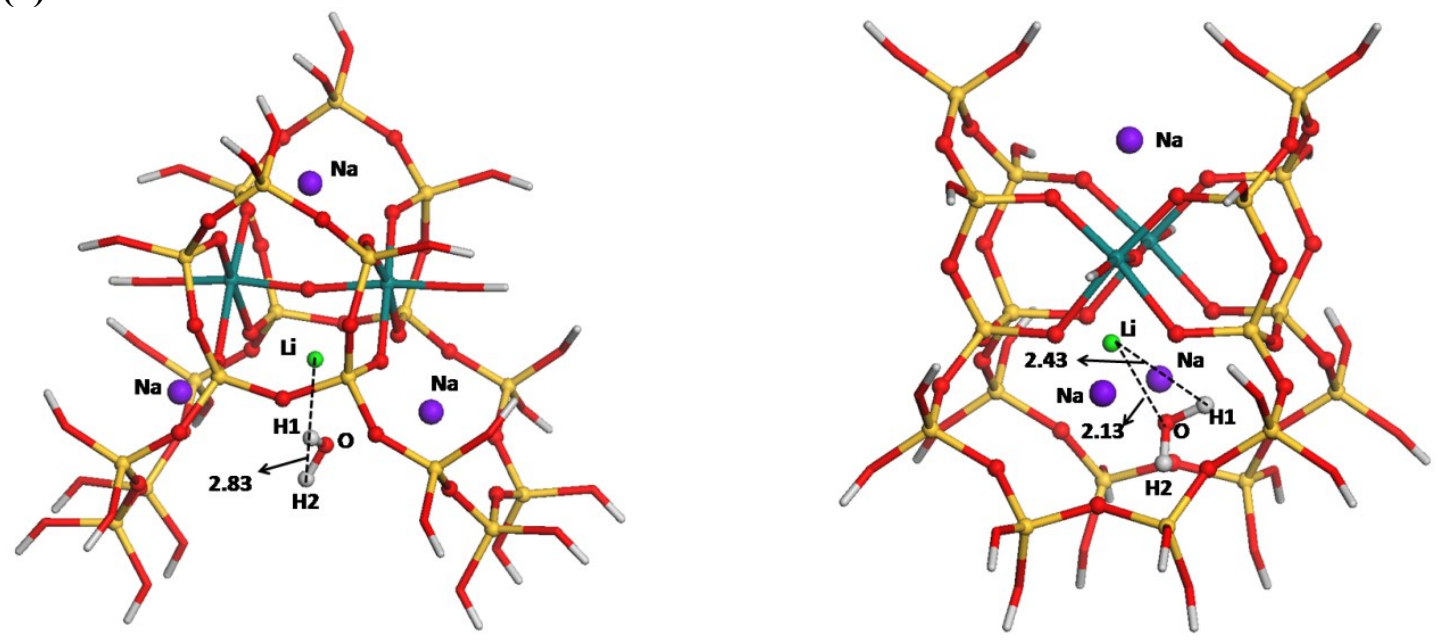

(b)
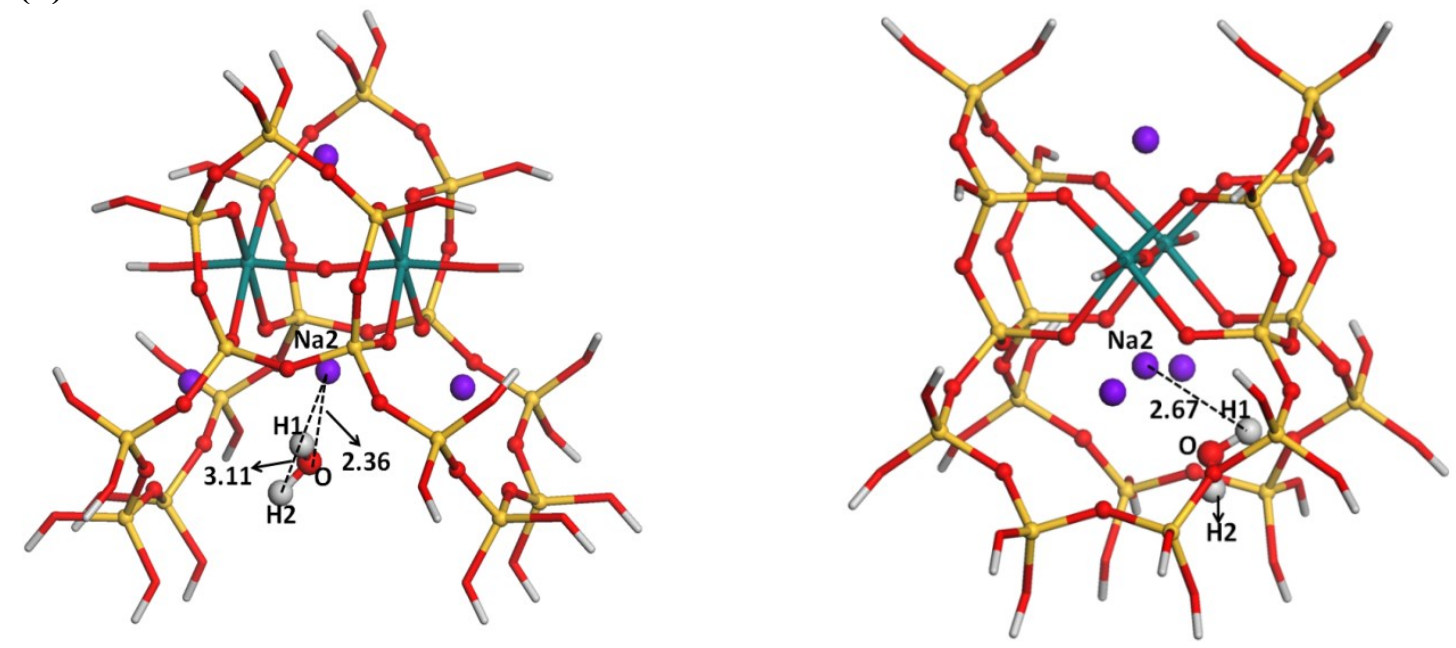

(c)
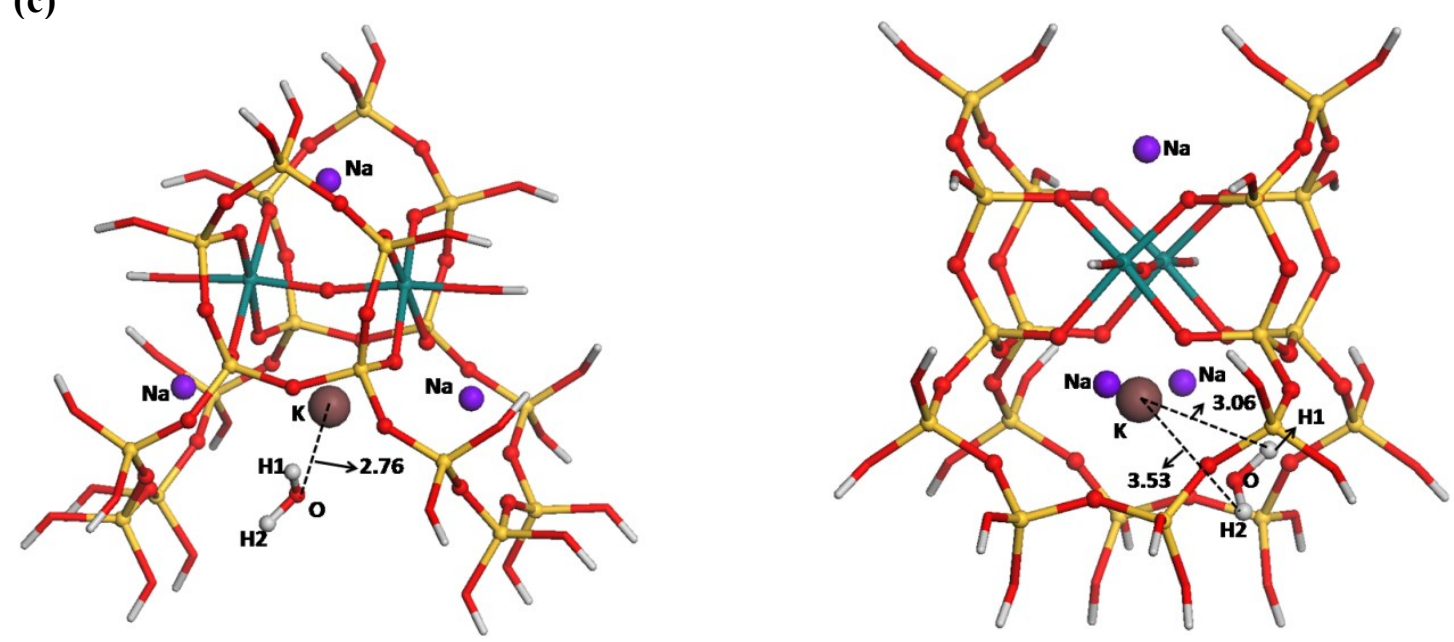
(d)
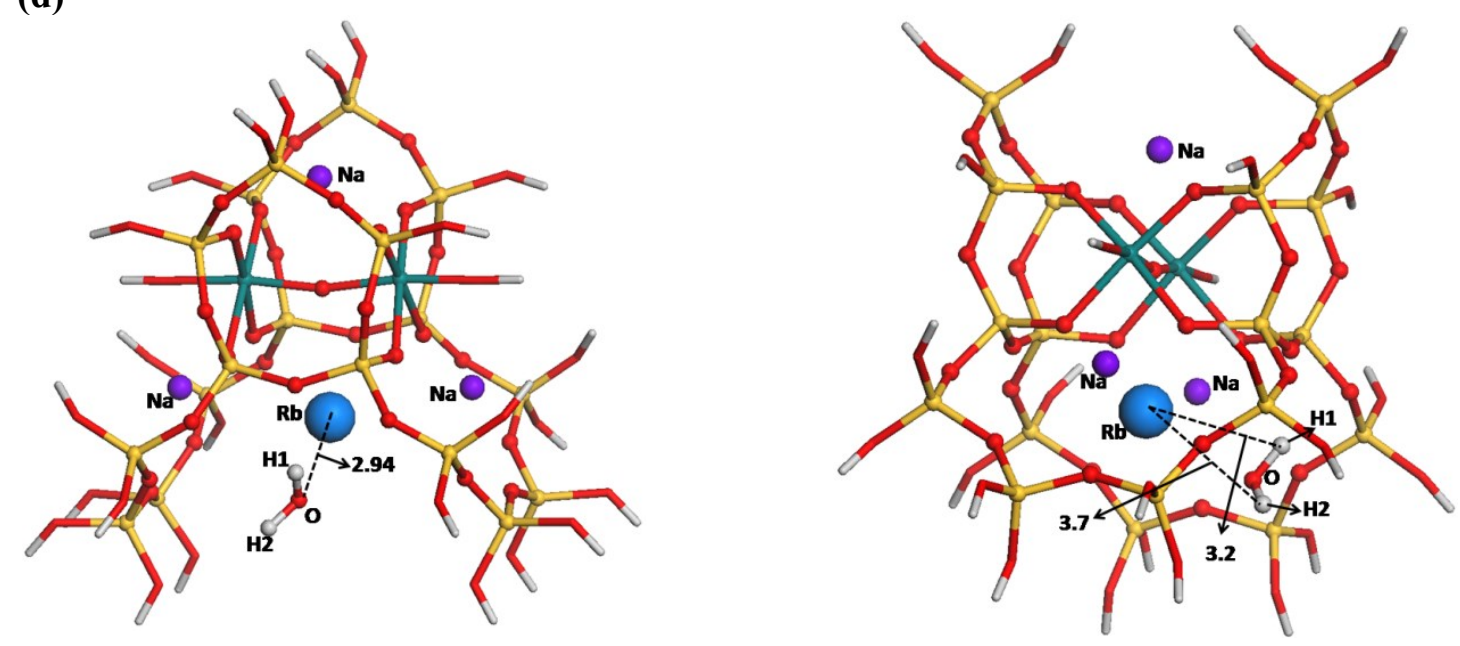

(e)
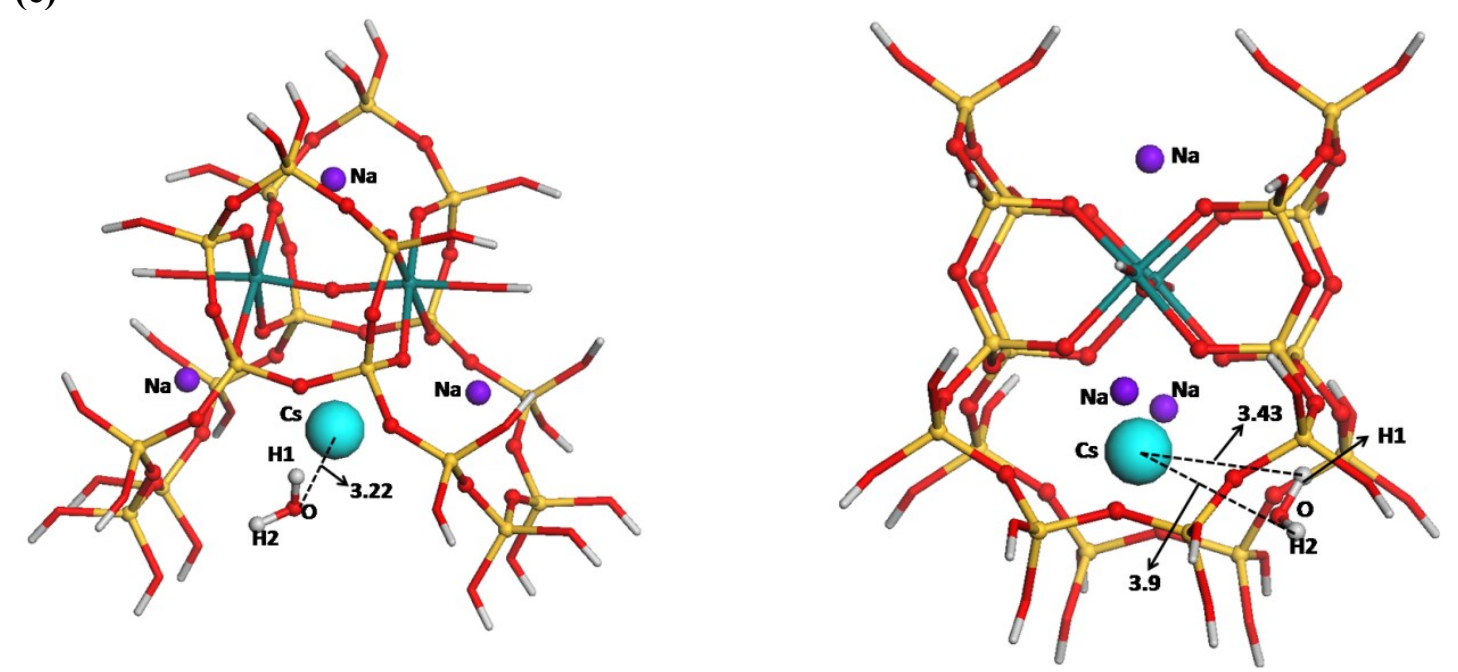

Figure S4. Configurations optimized with the M06-L approach and the counterpoise method for $\mathrm{H}_{2} \mathrm{O}$ interacting with Li-3Na-ETS-10 (a), Na-3Na-ETS-10 (b), K-3Na-ETS-10 (c), Rb3Na-ETS-10 (d), and Cs-3Na-ETS-10 (e), viewed along directions parallel (left) and normal (right) to the - Ti-O-Ti- chain. Dashed lines show the distances between the $\mathrm{M}_{\text {III }}$ ion and each individual atom of the sorbate. Color code is the same as in Figure S1. 
a)

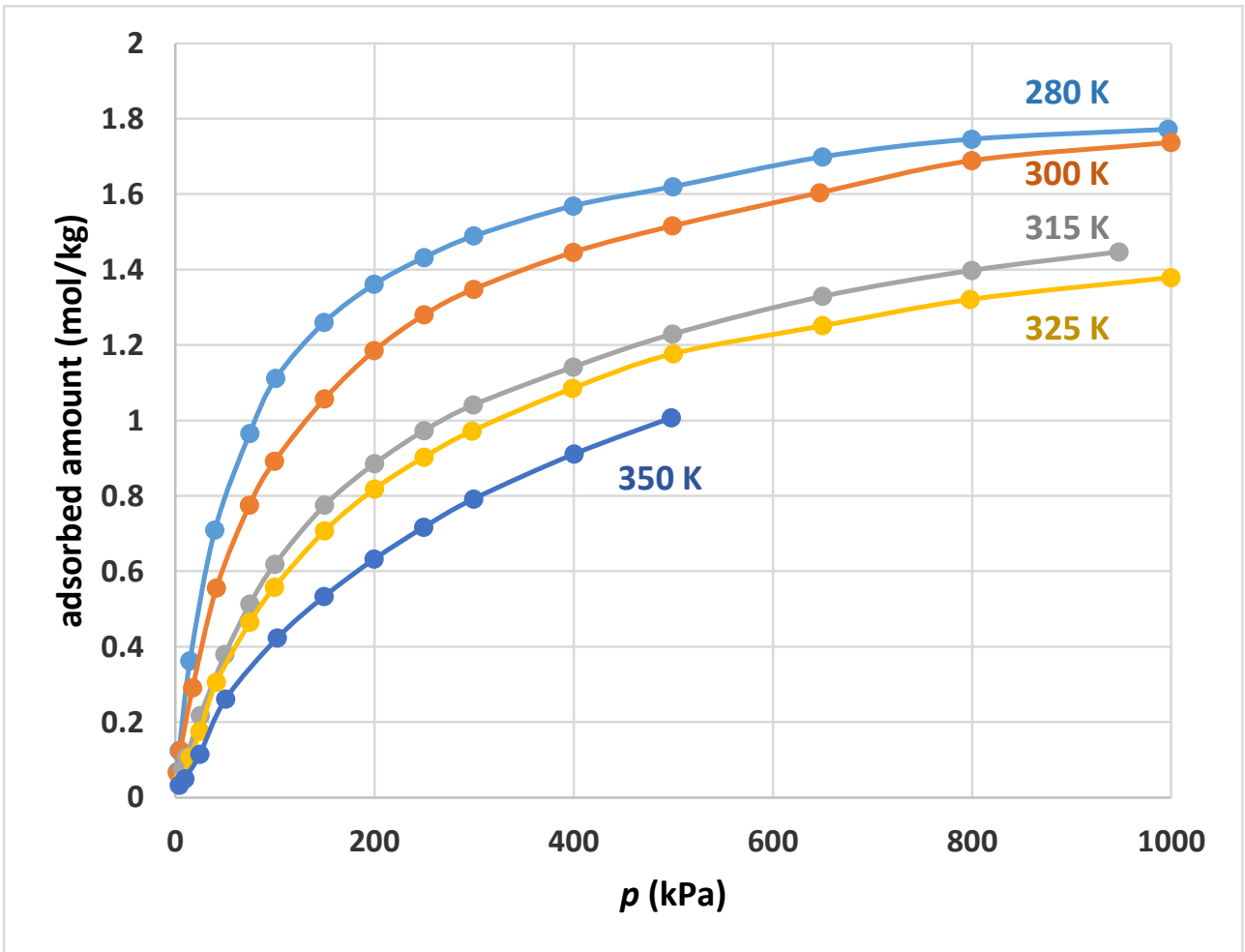

b)

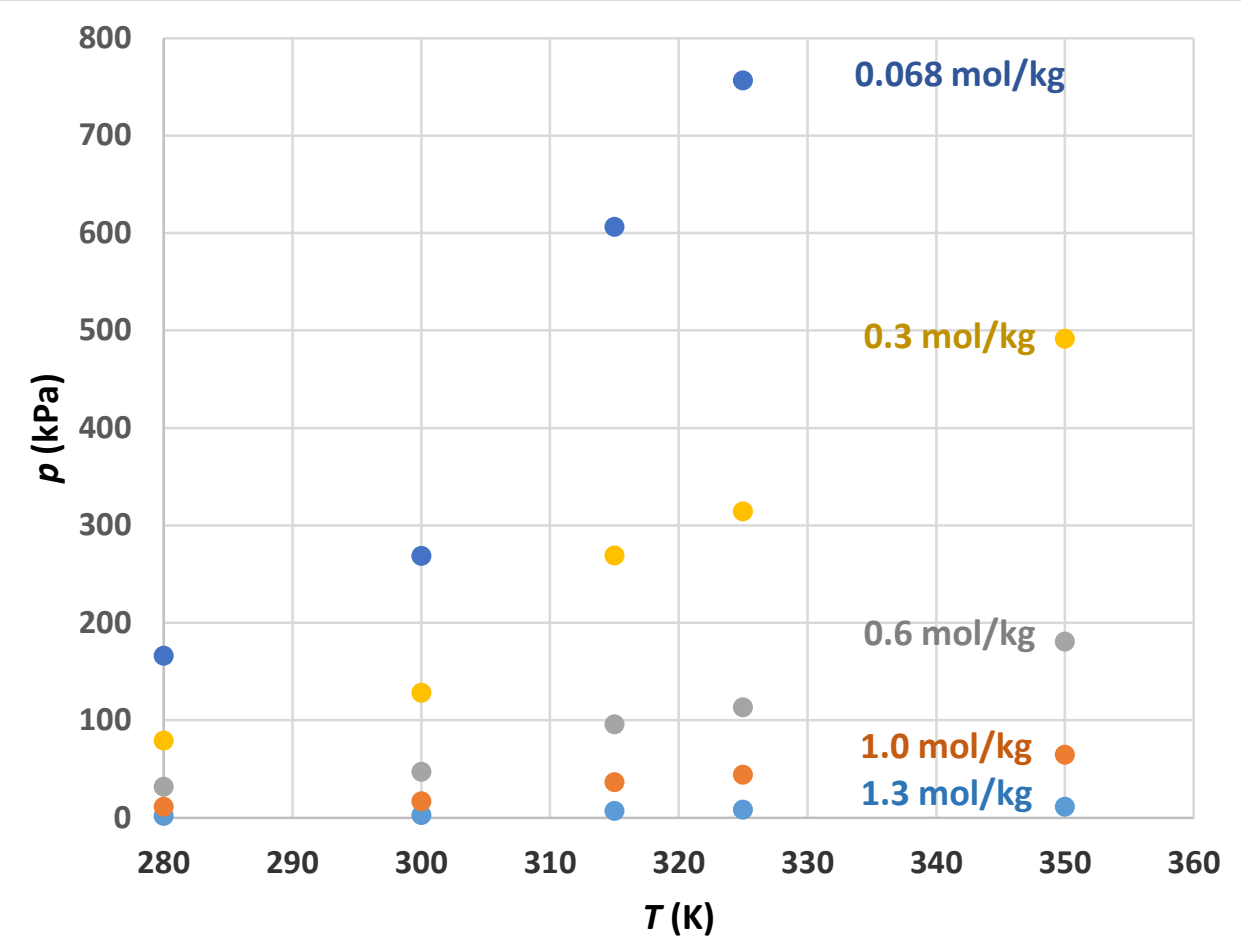




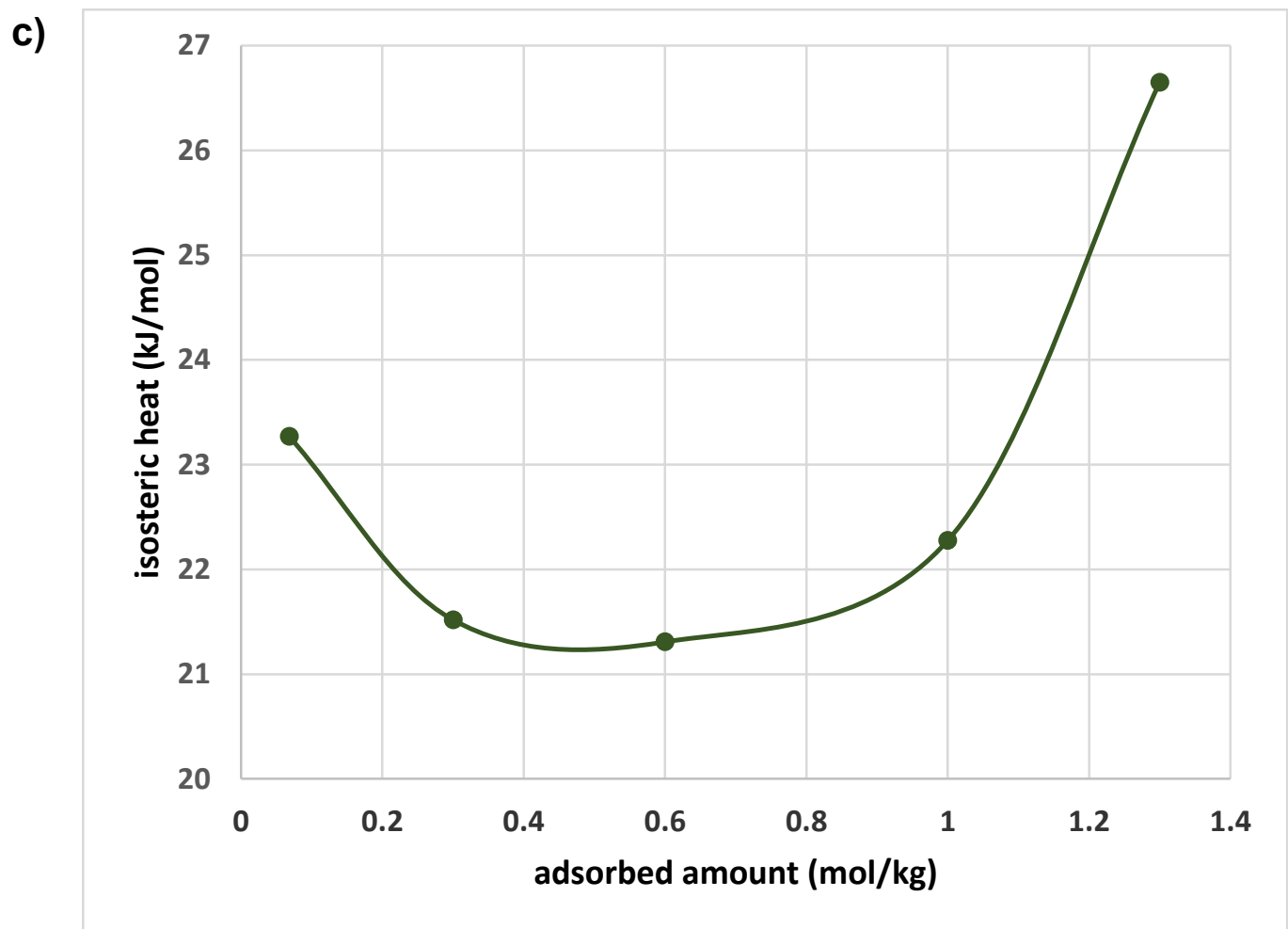

Figure S5. Adsorption isotherms at temperatures $280 \mathrm{~K}, 300 \mathrm{~K}, 315 \mathrm{~K}, 325 \mathrm{~K}$ and $350 \mathrm{~K}$ (a), Clausius-Clapeyron plots determined for five different adsorbed amounts of methane (b) and corresponding isosteric heats of adsorption (c) in Na-ETS-10. Experimental data used to plot the experimental adsorption isotherms were taken from the Supporting Information of AlBaghli et al. [5]. 


\section{References}

[1] X. Yang, J.-L. Paillaud, H.F.W.. van Breukelen, H. Kessler, E. Duprey, Synthesis of microporous titanosilicate ETS-10 with TiF4 or TiO2, Microporous Mesoporous Mater. 46 (2001) 1-11. doi:10.1016/S1387-1811(01)00267-0.

[2] S.B. Waghmode, R. Vetrivel, S.G. Hegde, C.S. Gopinath, S. Sivasanker, Physicochemical Investigations of the Basicity of the Cation Exchanged ETS-10 Molecular Sieves, J. Phys. Chem. B. 107 (2003) 8517-8523. doi:10.1021/jp0278622.

[3] B. Mihailova, V. Valtchev, S. Mintova, L. Konstantinov, Vibrational spectra of ETS-4 and ETS-10, Zeolites. 16 (1996) 22-24. doi:10.1016/0144-2449(95)00098-4.

[4] T.K. Das, A.J. Chandwadkar, A.P. Budhkar, S. Sivasanker, Studies on the synthesis of ETS-10 II. Use of organic templates, Microporous Mater. 5 (1996) 401-410. doi:10.1016/0927-6513(95)00075-5.

[5] N.A. Al-Baghli, K.F. Loughlin, Adsorption of Methane, Ethane, and Ethylene on Titanosilicate ETS-10 Zeolite, J. Chem. Eng. Data. 50 (2005) 843-848. doi:10.1021/je0496793. 